\title{
General Solution for Stabilizing Triple Helical Collagen
}

\author{
Yitao Zhang, Madison Herling, and David M. Chenoweth* \\ Department of Chemistry, University of Pennsylvania, 231 South 34th Street, \\ Philadelphia, Pennsylvania 19104-6323, United States
}

Table of contents

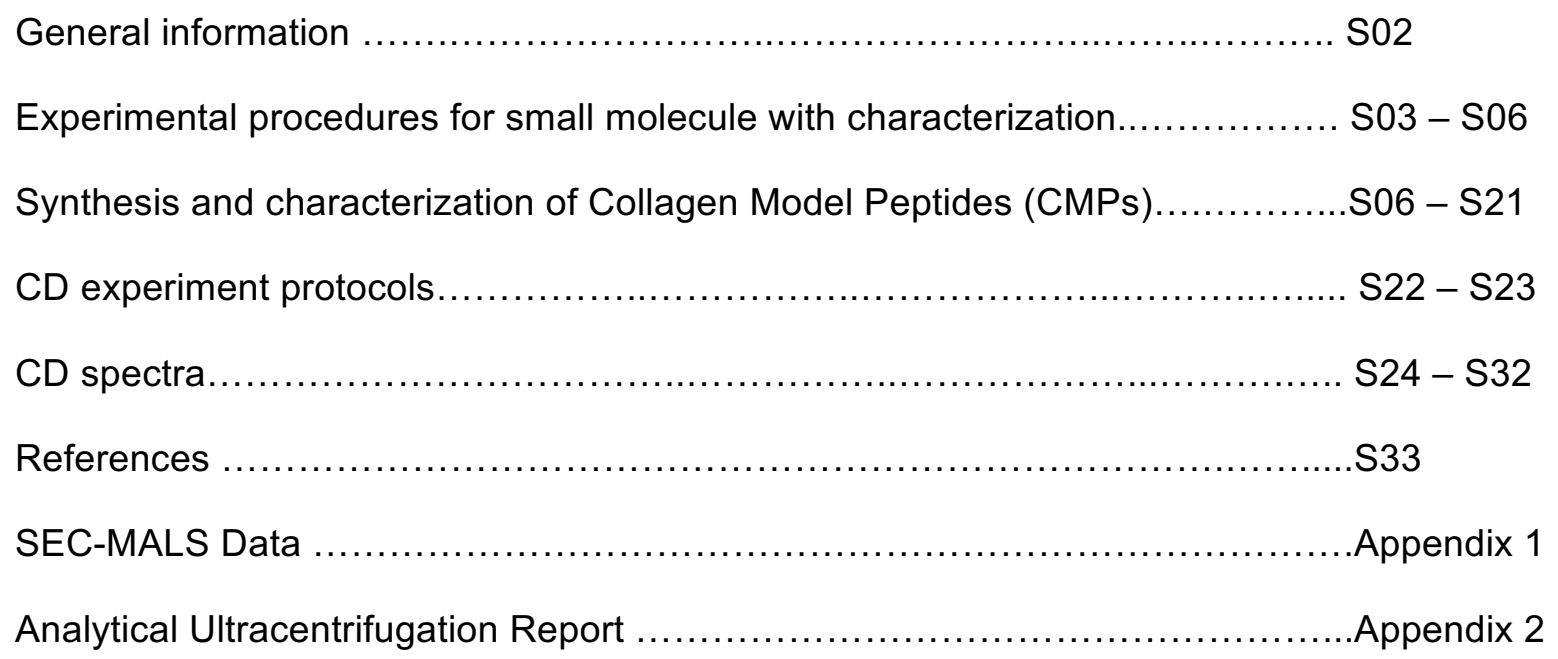




\section{General information}

All commercial reagents and solvents were used as received. Fmoc-Pro-OH, Fmoc-Gly-OH, HATU and Rink Amide AM Resin (100-200 mesh) were purchased from Novabiochem. Fmoc$\mathrm{Hyp}(\mathrm{tBu})-\mathrm{OH}$ was purchased from Advanced Chemtech. Piperidine was purchased from American Bioanalytical. All remaining chemicals were purchased from Sigma Aldrich. Flash column chromatography was performed using Silicycle silica gel (55-65 ^̊ pore diameter) or using an ISCO flash chromatography system. Thin-layer chromatography was performed on Sorbent Technologies silica plates $(250 \mu \mathrm{m}$ thickness). High-resolution mass spectra were obtained at the University of Pennsylvania's Mass Spectrometry Service Center on a Micromass AutoSpec electrospray/chemical ionization spectrometer. Molecular masses of long peptides were obtained via a Bruker Ultraflex III Matrix-assisted laser desorption/ionization (MALDI) mass spectrometer. Ultraviolet absorption spectrophotometry was performed on a JASCO V-650 spectrophotometer with a PAC-743R multichannel Peltier using quartz cells with a $1 \mathrm{~cm}$ cell path length. High performance liquid chromatography analysis was performed using a Jasco HPLC instrument equipped with a Phenomenex column (Luna 5u C18(2) 100A; $250 \times 4.60 \mathrm{~mm}, 5 \mu \mathrm{m}$ ). Circular dichroism experiments were performed with a Jasco J-1500 CD Spectrometer with a 6-cell holder. 


\section{Experimental procedures on small molecule}
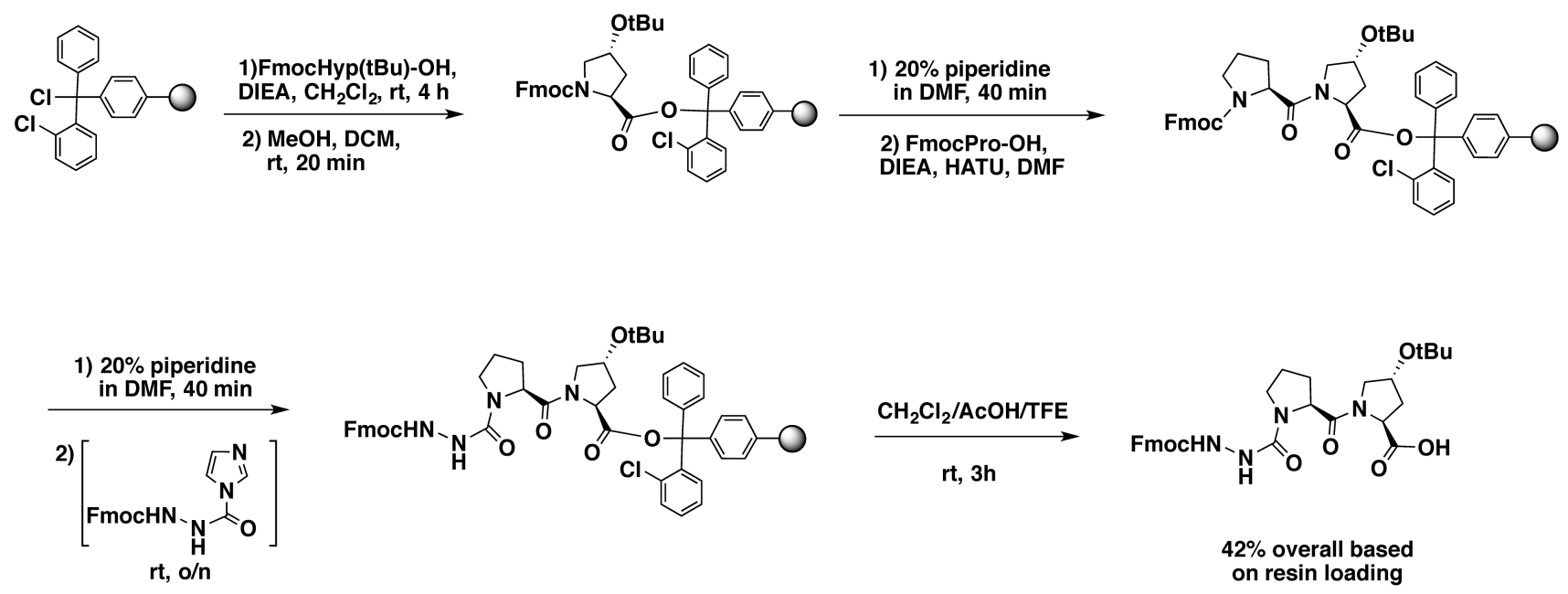

Scheme S1. Synthesis of Fmoc-azGly-Pro-Hyp(tBu)-OH.

Fmoc-azGly-Pro-Hyp(tBu)-OH

For the synthesis of Fmoc-azGly-Pro-Hyp(tBu)-OH, 2-chlorotrityl chloride resin was used. To a solution of Fmoc-Hyp(tBu)-OH (5 g, $12 \mathrm{mmol})$ in anhydrous $\mathrm{CH}_{2} \mathrm{Cl}_{2}(62 \mathrm{~mL})$, 2-chlorotrityl chloride resin $(5 \mathrm{~g}, 8.5 \mathrm{mmol}, 1.7 \mathrm{mmol} / \mathrm{g})$ and DIEA $(2.12 \mathrm{~mL}, 12.2 \mathrm{mmol})$ were added under nitrogen. After agitating the mixture for 10 minutes, additional DIEA $(3.19 \mathrm{~mL}, 18.4 \mathrm{mmol})$ was added. After agitating for $\sim 4$ hours, HPLC grade methanol $(18 \mathrm{~mL})$ was added to cap any remaining reactive trityl groups. After 15-20 minutes, the reaction mixture was filtered, and the resin was washed with $\mathrm{CH}_{2} \mathrm{Cl}_{2}$ $(6 \times 50 \mathrm{~mL})$ and left to air-dry overnight. The loading was measured according to a known protocol ${ }^{1}$ and found to be $0.75 \mathrm{mmol} / \mathrm{g}$. The total mass obtained from the batch was $5.27 \mathrm{~g} \mathrm{(3.94} \mathrm{mmol).}$

The Hyp(tBu)-loaded 2-chlorotrityl chloride resin (3.73 g, $2.85 \mathrm{mmol}, 1$ equiv) was suspended in DMF with stirring ( 30 min). After draining the DMF used to swell the resin, the base labile Fmocprotecting group was removed with $20 \%$ piperidine in DMF (30 mL, $20 \mathrm{~min}$, twice). The resin was washed with DMF (30 mL x 6). After deprotection, a solution of Fmoc-Pro-OH (2.88 g, 8.55 mmol), 
HATU (3.25 g, $8.55 \mathrm{mmol})$, and DIEA (3.0 ml, $18.31 \mathrm{mmol})$ in DMF (31 mL) was added to the resin after 5 minutes of activation. After 4 hours, the solution was drained, and the resin was washed with DMF (6x). The base labile Fmoc-protecting group was cleanly removed with $20 \%$ piperidine in DMF (30 mL, $20 \mathrm{~min}$, twice). The solution was drained, and the resin was washed with DMF (6x).

After deprotection, a solution of FmocNH-NH (2.17 $\mathrm{g}, 8.55 \mathrm{mmol})$ and carbonyldiimidazole $(1.39 \mathrm{~g}, 8.55 \mathrm{mmol})$ in $30 \mathrm{~mL}$ of DMF was prepared (510 minutes of stirring FmocNH- $\mathrm{NH}_{2}$ with carbonyldiimidazole at room temperature is sufficient to convert FmocNH-NH $\mathrm{H}_{2}$ to the acyl-activated form, which is the electrophile in the next coupling on solid phase). This solution was added to the aforementioned Pro-Hyp(tBu)-Resin, and the mixture was allowed to stir overnight at room temperature. The solution was drained, and another fresh batch of carbonyldiimidazole-activated Fmoc-hydrazine in DMF was added to the solid phase vessel, and the stirring was kept for another 6-12 hours at room temperature.

The resin was then collected via filtration, rinsed with DMF (1 X), $\mathrm{CH}_{2} \mathrm{Cl}_{2}(6 \mathrm{X})$, and dried under vacuum for 6 hours. The dried resin was treated with an $80 \% \mathrm{CH}_{2} \mathrm{Cl}_{2}(150 \mathrm{~mL}), 10 \% \mathrm{AcOH}(15 \mathrm{~mL})$, and $10 \%$ TFE $(15 \mathrm{~mL})$ cocktail solution for 3 hours at room temperature. The mixture was filtered through cotton, and the filtrate was concentrated in vacuo. AcOH was removed by azeotroping with $\mathrm{C}_{6} \mathrm{H}_{6}(3 \mathrm{x} 120 \mathrm{~mL})$. The resulting foamy solid residue was purified by silica gel column chromatography $\left(0 \%-5 \% \mathrm{MeOH}\right.$ in $\left.\mathrm{CH}_{2} \mathrm{Cl}_{2}\right)$. The isolated yield for this compound was $670 \mathrm{mg}$, which corresponds to a $42 \%$ yield based on determined Hyp(tBu)-loaded trityl resin active-sites.

TLC $\left(10 \% \mathrm{MeOH}\right.$ in $\left.\mathrm{CH}_{2} \mathrm{Cl}_{2}\right) \mathrm{R} f=0.09$.

${ }^{1} \mathbf{H}$ NMR $\left(500 \mathrm{MHz}, \mathrm{CDCl}_{3}\right) \delta$ 7.77-7.00 (m, 10H), 4.62-4.22 (m, 5H), 4.22-3.31 (m, 5H), 2.65-1.77 (m, 6H), $1.11(\mathrm{~s}, 9 \mathrm{H})$. 
${ }^{13} \mathbf{C}$ NMR $\left(125 \mathrm{MHz}, \mathrm{CDCl}_{3}\right) \delta 173.8,173.0,157.6,156.9,143.7,141.1,127.6,127.0,125.3,125.2$, $119.8,74.2,69.5,67.7,58.4,58.0,53.1,46.8,45.9,36.0,28.1,24.6$.

HRMS (ESI) calculated for $\mathrm{C}_{30} \mathrm{H}_{36} \mathrm{~N}_{4} \mathrm{O}_{7}[\mathrm{M}+\mathrm{Na}]^{+}$587.2476, found 587.2485.

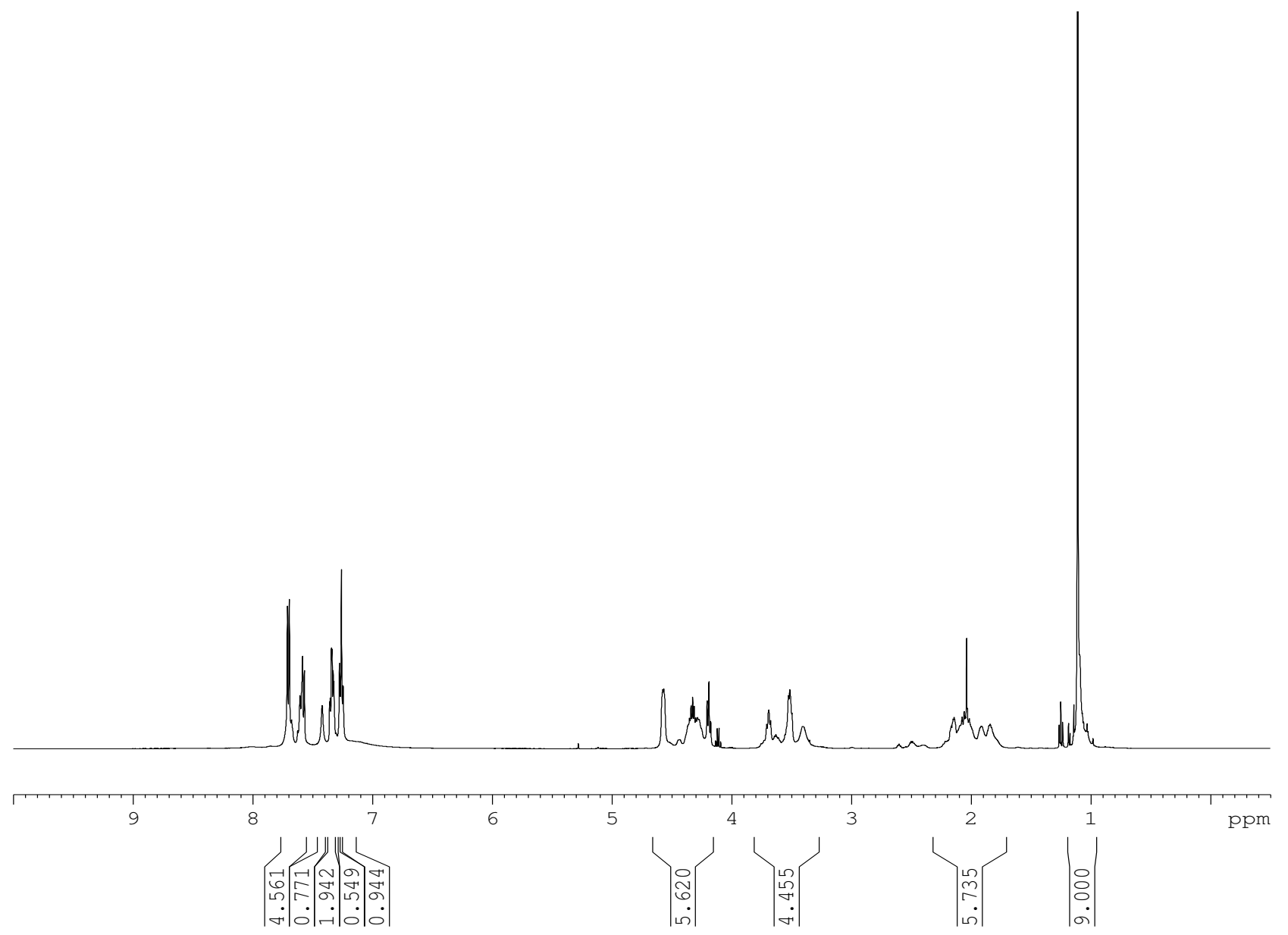

Figure S1 ${ }^{1} \mathrm{H}$ NMR of Fmoc-azGlyProHyp(tBu)-OH 


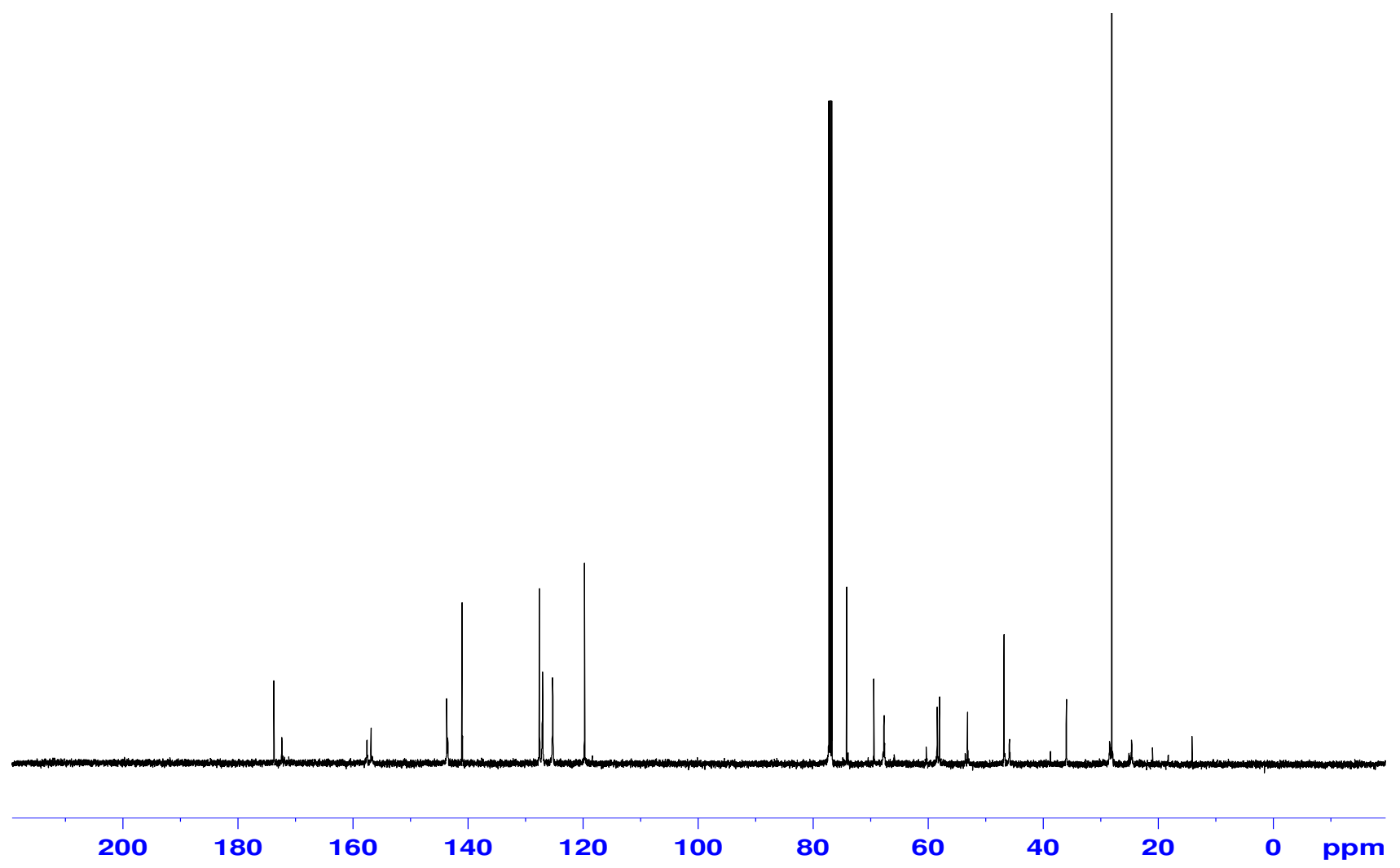

Figure S2 ${ }^{13} \mathrm{C}$ NMR of Fmoc-azGlyProHyp(tBu)-OH

\section{Synthesis and Purification of Collagen Model Peptides}

\section{General protocols}

\section{Protocol A - Resin preparation followed by Fmoc-deprotection}

The peptides used in this paper were synthesized by manual SPPS method with Rink Amide AM resin $(0.54 \mathrm{mmol} / \mathrm{g})$ on a $0.02-\mathrm{mmol}$ scale. Rink Amide resin $(37 \mathrm{mg})$ was carefully weighed out and transferred to a $5 \mathrm{~mL}$ solid phase synthesis vessel. The resin was then swelled in $4 \mathrm{~mL}$ of DMF for 30 min. After draining, the resin was treated with piperidine in DMF $(20 \% \mathrm{v} / \mathrm{v})(1 \mathrm{~mL})$ at ambient temperature with stirring for 15 minutes $(2 \mathrm{x})$. The solution was drained, and the resin was washed with DMF (6x). An alternative deprotection protocol is shown at the end of this section (see below). 


\section{Protocol B - Oligopeptide building block coupling followed by Fmoc-deprotection}

Fmoc-Xaa-Yaa-Gly-OH (3 equiv) and HATU (3 equiv) were dissolved in DMF (0.67 mL). DIEA (6 equiv) was subsequently added to the mixture, and the entire solution was transferred to the reaction vessel containing the resin. The mixture was stirred for 60-80 min, drained, and washed with DMF (6x). The resin was treated with piperidine in DMF $(20 \% \mathrm{v} / \mathrm{v})(1 \mathrm{~mL})$ at ambient temperature with stirring for 15 minutes $(2 \mathrm{x})$. The solution was drained, and the resin was thoroughly washed with $\operatorname{DMF}(6 \mathrm{x})$.

\section{Protocol B' - Single amino acid coupling followed by Fmoc-deprotection}

Fmoc-Aa-OH (3 equiv) and HATU (3 equiv) were dissolved in DMF (0.67 mL). DIEA (6 equiv) was subsequently added to the mixture, and the entire solution was transferred to the vessel containing amino-functionalized resin. The mixture was stirred for 45-60 min, drained, and washed with DMF (6x). The resin was treated with piperidine in DMF $(20 \% \mathrm{v} / \mathrm{v})(1 \mathrm{~mL})$ at ambient temperature with stirring for 15 minutes $(2 \mathrm{x})$. The solution was drained and the resin was washed with DMF (6x).

\section{Protocol B" - Special coupling of FmocNH-NH $\mathrm{N}_{2}$ followed by Fmoc-deprotection}

Carbonyldiimidazole (3 equiv) was dissolved in DMF $(0.67 \mathrm{~mL})$. FmocNH- $\mathrm{NH}_{2}$ (3 equiv) was subsequently added to the solution. After 5-10 minutes activation at room temperature, the mixture was transferred to the vessel containing amino-functionalized resin. The mixture was stirred for overnight at room temperature, drained, and "recharged" with a fresh batch of in-situ generated FmocNH- $\mathrm{NH}_{2} / \mathrm{CDI}$ solution. After another 6-10 hours, the solution was drained, and the resin was washed with DMF (6x). The resin was treated with piperidine in DMF (20\% v/v) (1 mL) at ambient temperature with stirring for 15 minutes $(2 \mathrm{x})$. The solution was drained, and the resin was washed with DMF (6x).

Protocol B" - Special coupling of FmocHyp(tBu)-OH (or Fmoc-azGly-Pro-Hyp(tBu)-OH) onto azGly followed by Fmoc-deprotection

Fmoc-Hyp(tBu)-OH (3 equiv) was dissolved in THF (0.67 mL). NMM (6 equiv) and isobutylchloroformate (3 equiv) were subsequently added to the solution. After 5-10 minutes at room 
temperature, the mixture was transferred to the vessel containing amino-functionalized resin. The mixture was stirred for 5-6 h at room temperature, drained, and washed with DMF (6x). The resin was treated with piperidine in DMF $(20 \% \mathrm{v} / \mathrm{v})(1 \mathrm{~mL})$ at ambient temperature with stirring for 15 minutes $(2 \mathrm{x})$. The solution was drained and the resin was washed with DMF (6x).

\section{Protocol C-Acylation}

A solution of NMM $(0.15 \mathrm{~mL})$ and $\mathrm{Ac}_{2} \mathrm{O}(0.25 \mathrm{~mL})$ in DMF $(2.1 \mathrm{~mL})$ were added to the aminofunctionalized resin. This mixture was stirred for 20 minutes at room temperature $(2 \mathrm{x})$. The solution was drained and thoroughly washed with $\mathrm{CH}_{2} \mathrm{Cl}_{2}(6 \mathrm{x})$.

\section{Protocol D- Cleavage off the resin and collection of the crude product}

The resin was suspended for $35 \mathrm{~min}$ in a $4-\mathrm{mL}$ mixture of $\mathrm{TFA} / \mathrm{H}_{2} \mathrm{O} / \mathrm{TIPS}(95: 2.5: 2.5)$ at room temperature. Argon was used to push the mixture through the filter of the vessel, and the filtrate was collected and dropwise added to cold $\mathrm{Et}_{2} \mathrm{O}(\sim 11 \mathrm{~mL})$. The sample was cooled to $4{ }^{\circ} \mathrm{C}$ for approximately $1 \mathrm{~h}$, during which white solid precipitated. The resulted mixture was centrifuged and the supernatant was decanted. The white solid was dissolved in water (HPLC grade) and refrigerated at $4{ }^{\circ} \mathrm{C}$ before HPLC purification.

\section{Protocol E- HPLC purification}

MeCN (B) and water containing 0.1\% TFA (A) were used as eluents. The flow rates used for semipreparative HPLC and analytical HPLC were $4 \mathrm{~mL} / \mathrm{min}$ and $1 \mathrm{~mL} / \mathrm{min}$, respectively. Crude samples were heated to $80^{\circ} \mathrm{C}$ for $10-15$ min before injection to prevent early triple helix formation.

An alternative Fmoc-deprotection method was used by treating the resin with a solution of 2\% (v/v) $\mathrm{DBU}, 1 \% \mathrm{HOBt}(\mathrm{m} / \mathrm{v})$ in DMF. The resin is immersed in $1 \mathrm{~mL}$ of the above-mentioned solution for 1 minute followed by draining, and this process is repeated twice more (a total 3 doses of DBU/HOBt solution). When the growing peptide sequence was longer than nine amino acids, this method provided a slightly cleaner deprotection result compared to the traditional double treatment with piperidine/DMF solution. 


\section{Characterization of Collagen Model Peptides (CMPs).}

CMP 3 Ac-(Pro-Hyp-azGly)(Pro-Hyp-Gly) ${ }_{6}-\mathrm{NH}_{2}$

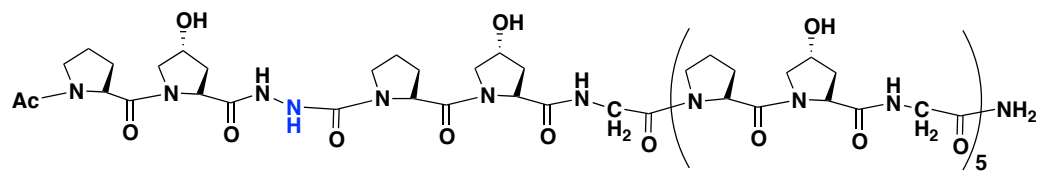

Synthesis: $\mathrm{A}+\mathrm{B}(\mathrm{POG})+\mathrm{B}(\mathrm{POG})+\mathrm{B}(\mathrm{POG})+\mathrm{B}(\mathrm{POG})+\mathrm{B}(\mathrm{POG})+\mathrm{B}(\mathrm{POG})+\mathrm{B}$ " $\left(\mathrm{FmocNH}^{\left.-\mathrm{NH}_{2}\right)}\right.$

$+\mathrm{B}^{\prime \prime}(\mathrm{O})+\mathrm{B}^{\prime}(\mathrm{P})+\mathrm{C}+\mathrm{D}+\mathrm{E}$

Note: POG refers to the tripeptide building block FmocProHyp(tBu)Gly-OH. Its synthesis was previously described by Moroder et al. ${ }^{3}$

The synthesis of Fmoc-hydrazine, FmocNH-NH${ }_{2}$, was previously reported. ${ }^{2}$

MALDI-MS calculated $[\mathrm{M}+\mathrm{Na}]^{+}$1952.89, found 1953.03
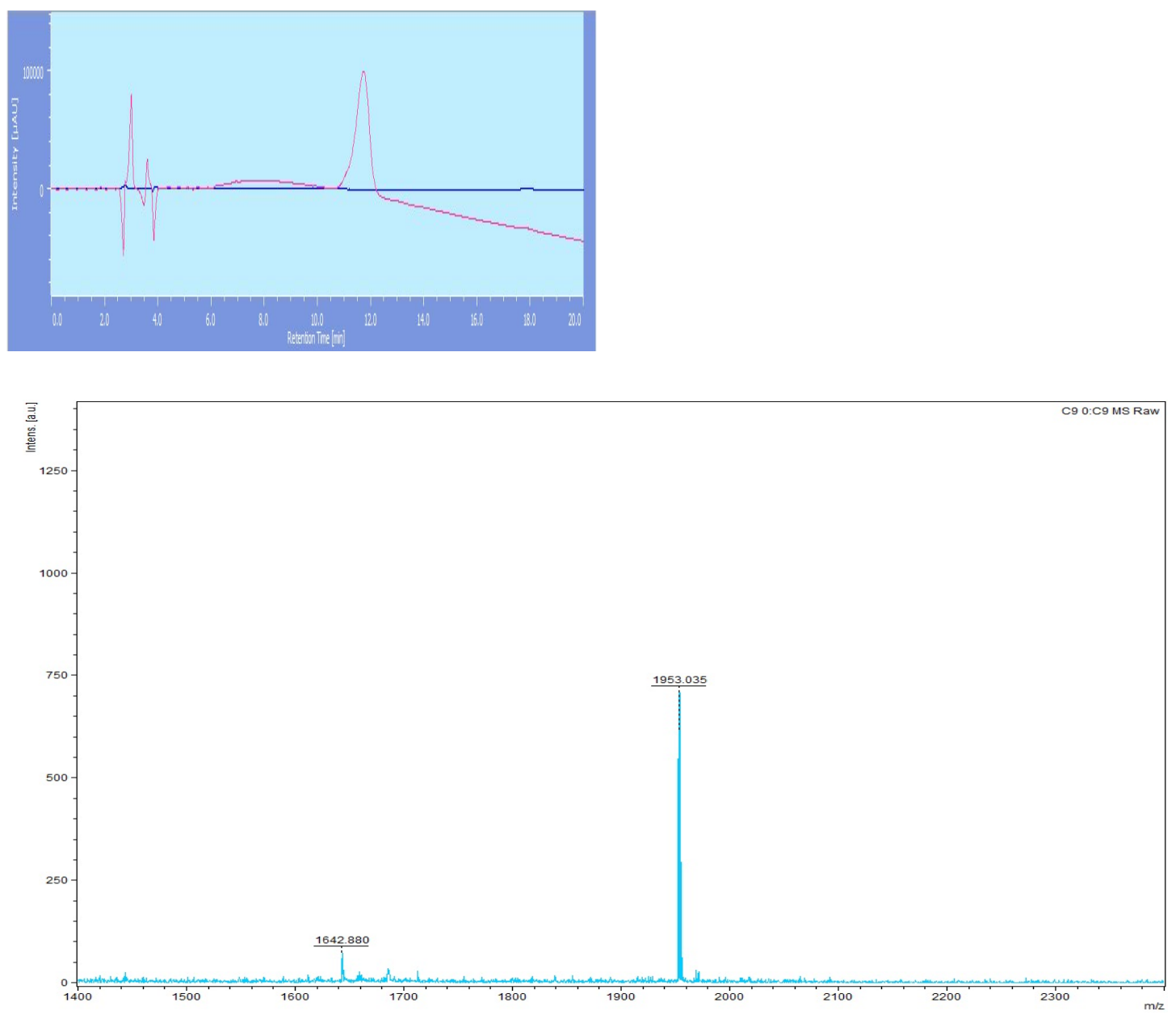
CMP 4 Ac-(Pro-Hyp-Gly)(Pro-Hyp-azGly)(Pro-Hyp-Gly) $)_{5}-\mathrm{NH}_{2}$

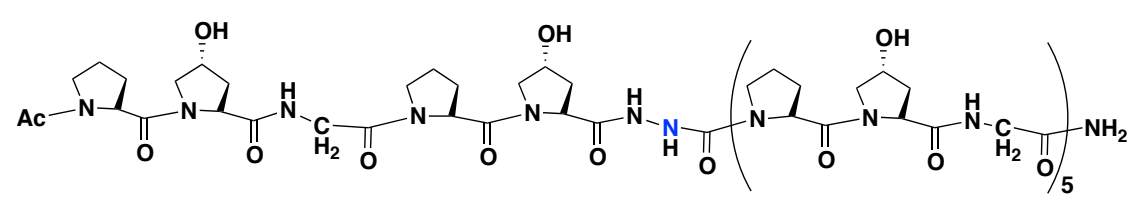

Synthesis: $\mathrm{A}+\mathrm{B}(\mathrm{POG})+\mathrm{B}(\mathrm{POG})+\mathrm{B}(\mathrm{POG})+\mathrm{B}(\mathrm{POG})+\mathrm{B}(\mathrm{POG})+\mathrm{B}$ ” $\left(\mathrm{FmocNH}^{-\mathrm{NH}_{2}}\right)+\mathrm{B}$ "' $(\mathrm{O})+$ $\mathrm{B}^{\prime}(\mathrm{P})+\mathrm{B}(\mathrm{POG})+\mathrm{C}+\mathrm{D}+\mathrm{E}$

MALDI-MS calculated [M+Na] ${ }^{+} 1952.89$, found 1953.21
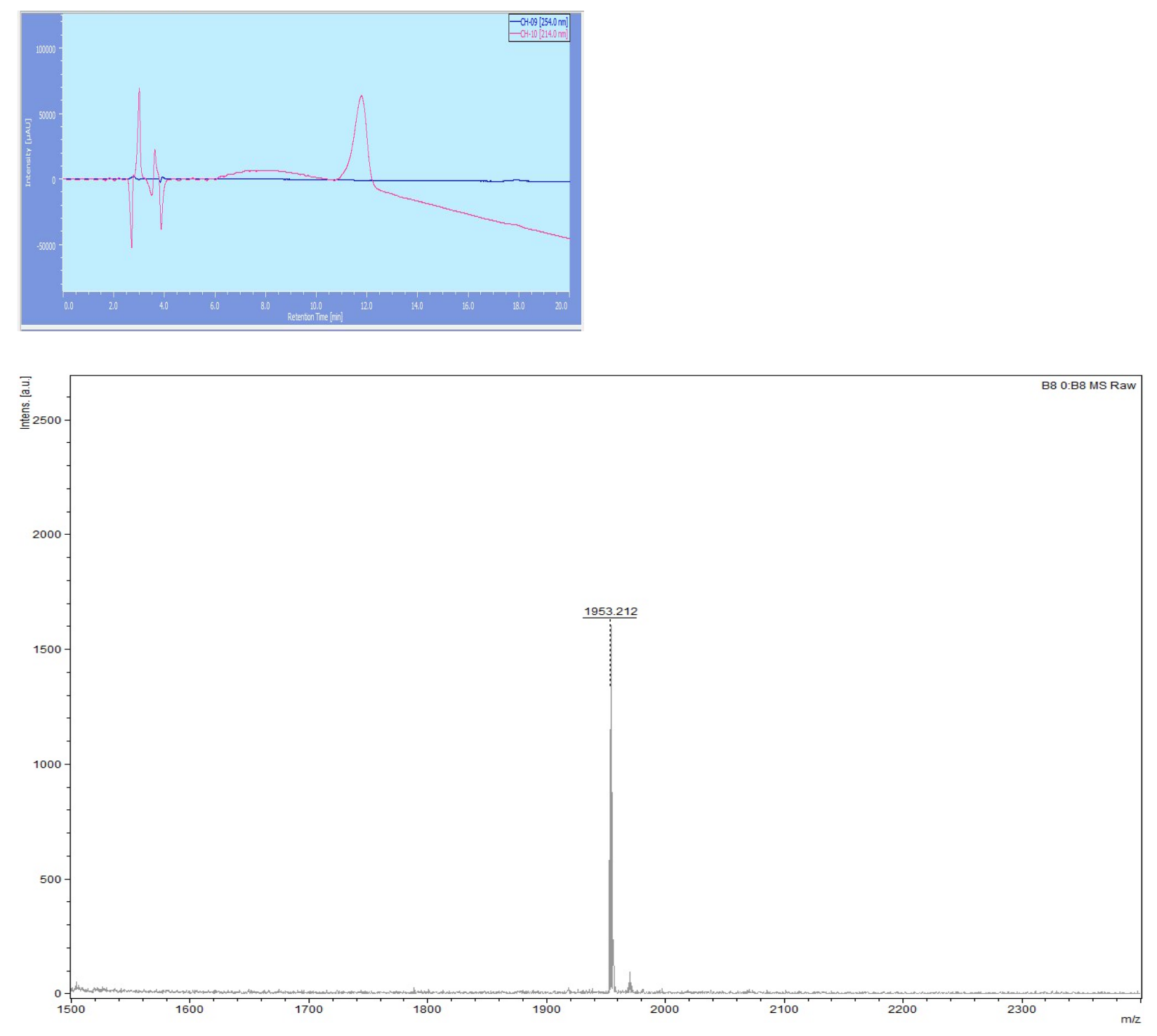
CMP 5 Ac-(Pro-Hyp-Gly) ${ }_{2}$ (Pro-Hyp-azGly)(Pro-Hyp-Gly) $)_{4}-\mathrm{NH}_{2}$

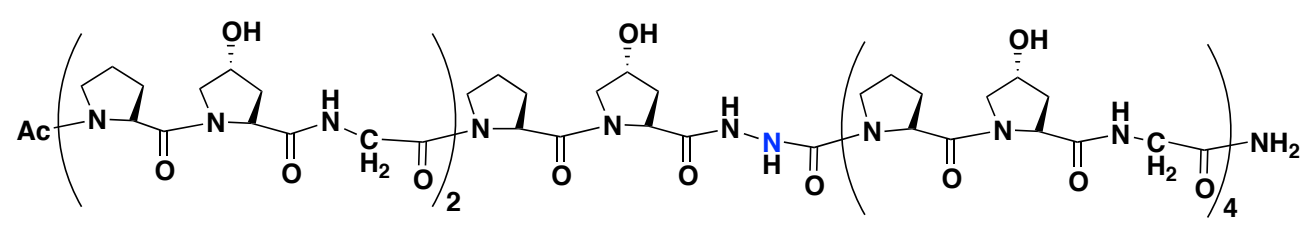

Synthesis: $\mathrm{A}+\mathrm{B}(\mathrm{POG})+\mathrm{B}(\mathrm{POG})+\mathrm{B}(\mathrm{POG})+\mathrm{B}(\mathrm{POG})+\mathrm{B}$ " $\left(\right.$ FmocNH-NH $\left.\mathrm{H}_{2}\right)+\mathrm{B}{ }^{\prime \prime}(\mathrm{O})+\mathrm{B}{ }^{\prime}(\mathrm{P})+$ $\mathrm{B}(\mathrm{POG})+\mathrm{B}(\mathrm{POG})+\mathrm{C}+\mathrm{D}+\mathrm{E}$

MALDI-MS calculated [M+Na] ${ }^{+}$1952.88, found 1952.86
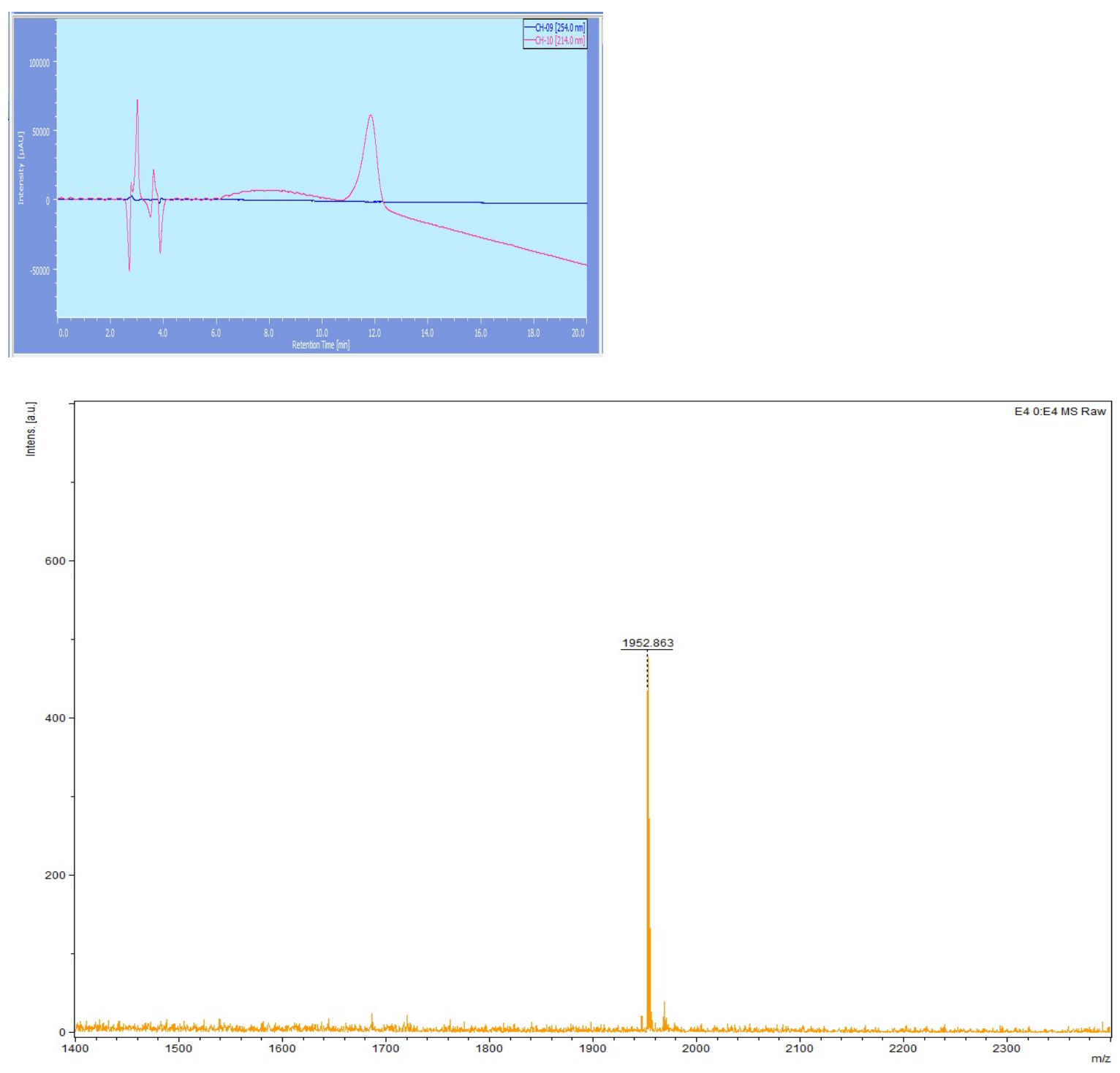
CMP 6 Ac-(Pro-Hyp-Gly) ${ }_{4}\left(\right.$ Pro-Hyp-azGly)(Pro-Hyp-Gly) ${ }_{2}-\mathrm{NH}_{2}$

$(\overbrace{\mathrm{N}}^{\mathrm{O}}$

Synthesis: A + B(POG) + B(POG) + B" $\left(\right.$ FmocNH-NH $\left.{ }_{2}\right)+\mathrm{B}^{\prime \prime}(\mathrm{O})+\mathrm{B}^{\prime}(\mathrm{P})+\mathrm{B}(\mathrm{POG})+\mathrm{B}(\mathrm{POG})+$ $\mathrm{B}(\mathrm{POG})+\mathrm{B}(\mathrm{POG})+\mathrm{C}+\mathrm{D}+\mathrm{E}$

MALDI-MS calculated $[\mathrm{M}+\mathrm{Na}]^{+}$1952.89, found 1953.45
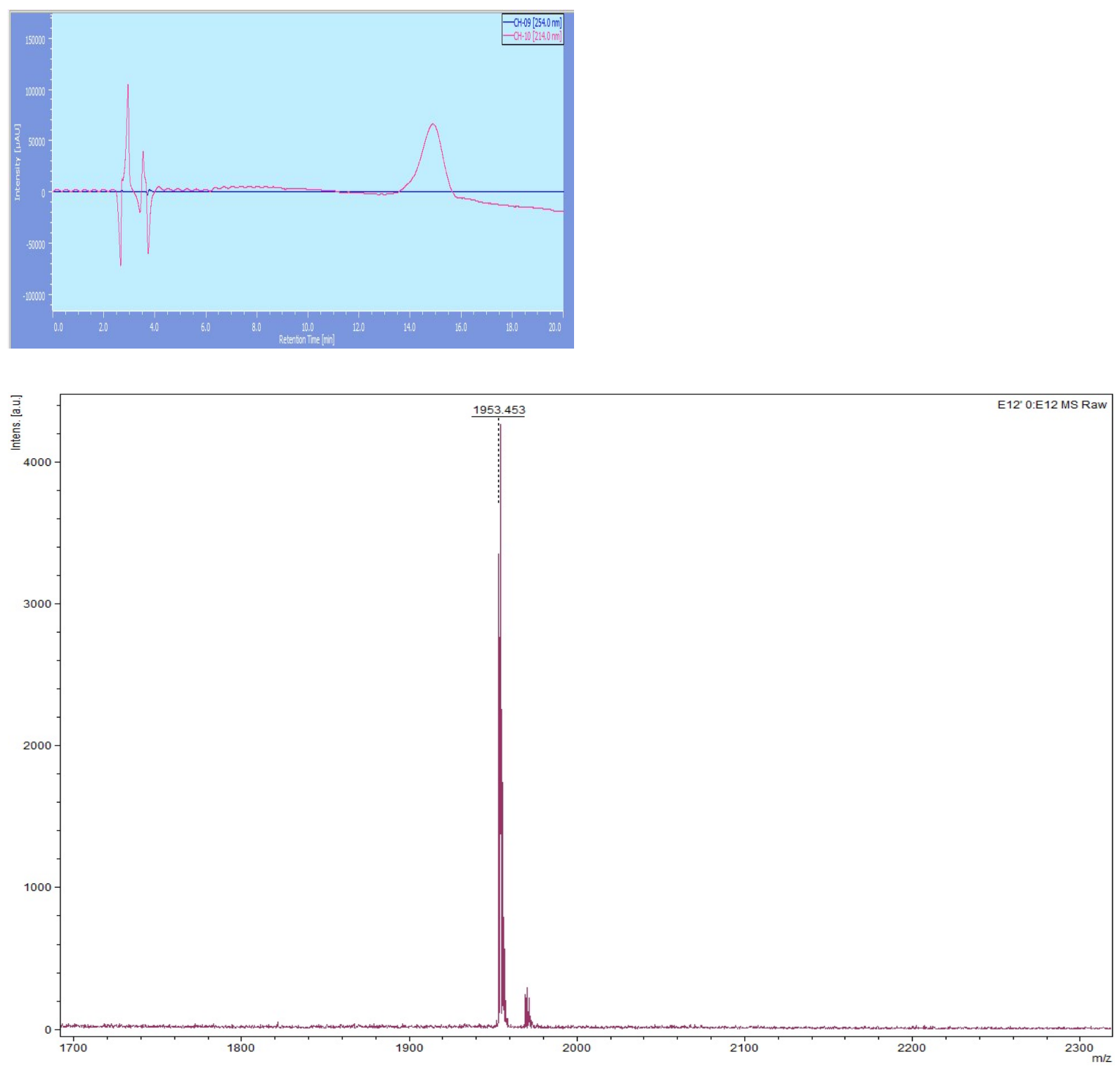
CMP 7 Ac-(Pro-Hyp-Gly) $)_{5}$ (Pro-Hyp-azGly)(Pro-Hyp-Gly)-NH ${ }_{2}$

(c)

Synthesis: $\mathrm{A}+\mathrm{B}(\mathrm{POG})+\mathrm{B}$ " $\left(\mathrm{FmocNH}-\mathrm{NH}_{2}\right)+\mathrm{B}{ }^{\prime \prime}(\mathrm{O})+\mathrm{B}(\mathrm{P})+\mathrm{B}(\mathrm{POG})+\mathrm{B}(\mathrm{POG})+\mathrm{B}(\mathrm{POG})+$ $\mathrm{B}(\mathrm{POG})+\mathrm{B}(\mathrm{POG})+\mathrm{C}+\mathrm{D}+\mathrm{E}$

MALDI-MS calculated [M+Na] ${ }^{+}$1952.89, found 1953.27
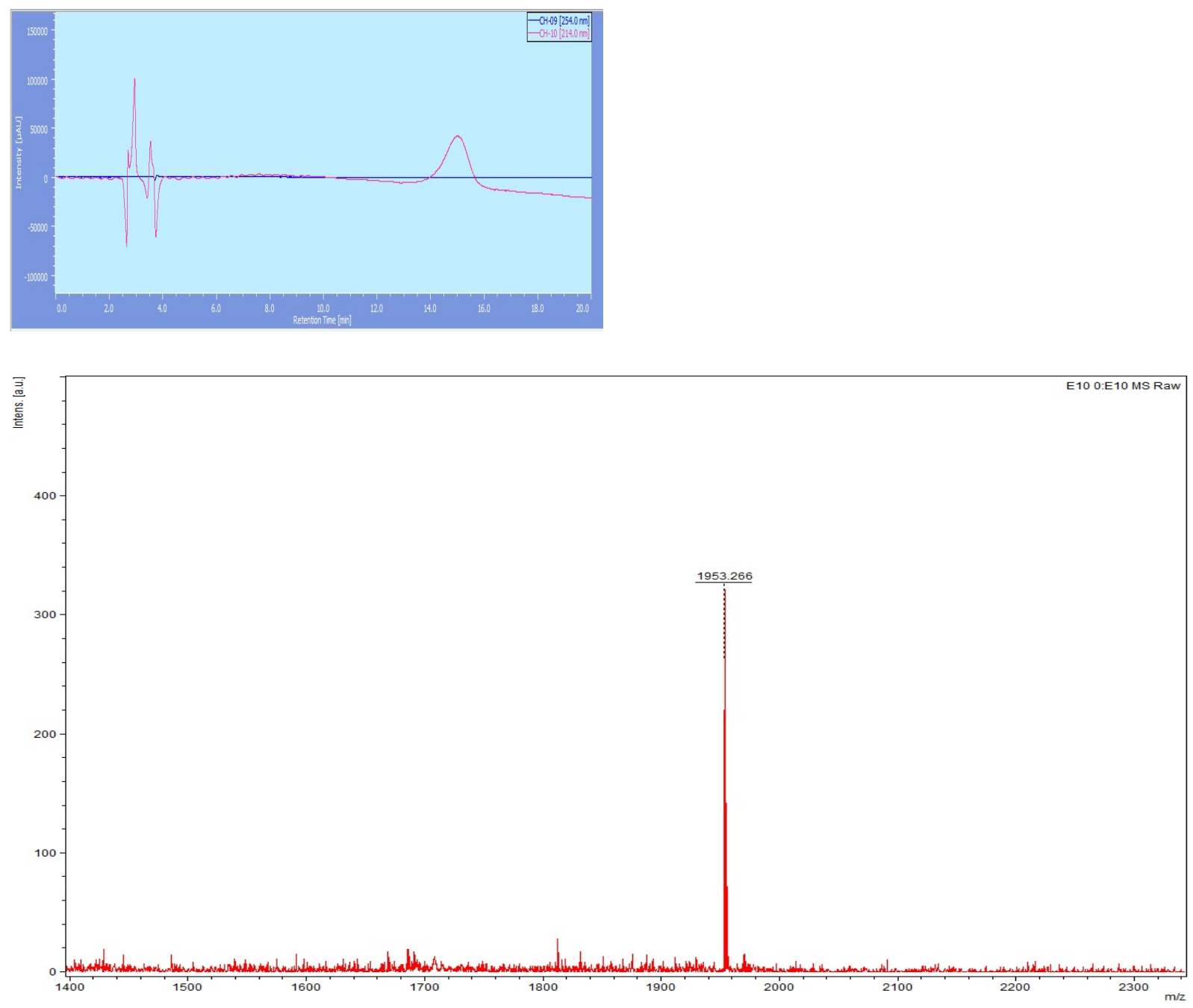
CMP 8 Ac-(Pro-Hyp-Gly)(Pro-Hyp-azGly)(Pro-Hyp-Gly) ${ }_{3}$ (Pro-Hyp-azGly)(Pro-Hyp-Gly)-NH ${ }_{2}$

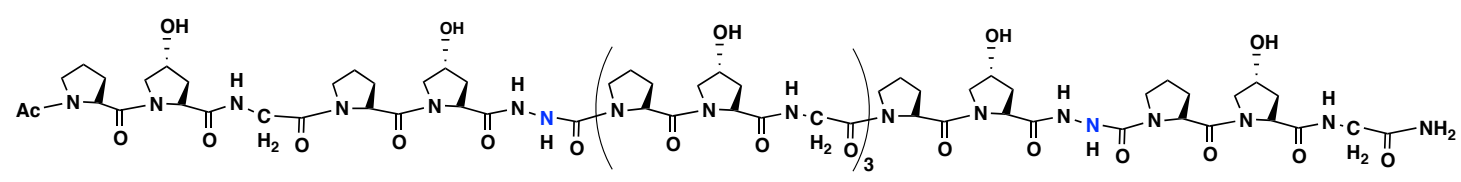

Synthesis: $\mathrm{A}+\mathrm{B}(\mathrm{POG})+\mathrm{B}$ ' $\left(\mathrm{FmocNH}-\mathrm{NH}_{2}\right)+\mathrm{B}{ }^{\prime \prime}(\mathrm{O})+\mathrm{B}(\mathrm{P})+\mathrm{B}(\mathrm{POG})+\mathrm{B}(\mathrm{POG})+\mathrm{B}(\mathrm{POG})+$ $\mathrm{B}$ ' $\left(\right.$ FmocNH-NH$\left.H_{2}\right)+\mathrm{B}{ }^{\prime \prime}(\mathrm{O})+\mathrm{B}(\mathrm{P})+\mathrm{B}(\mathrm{POG})+\mathrm{C}+\mathrm{D}+\mathrm{E}$

MALDI-MS calculated [M+Na] ${ }^{+}$1953.88, found 1954.06
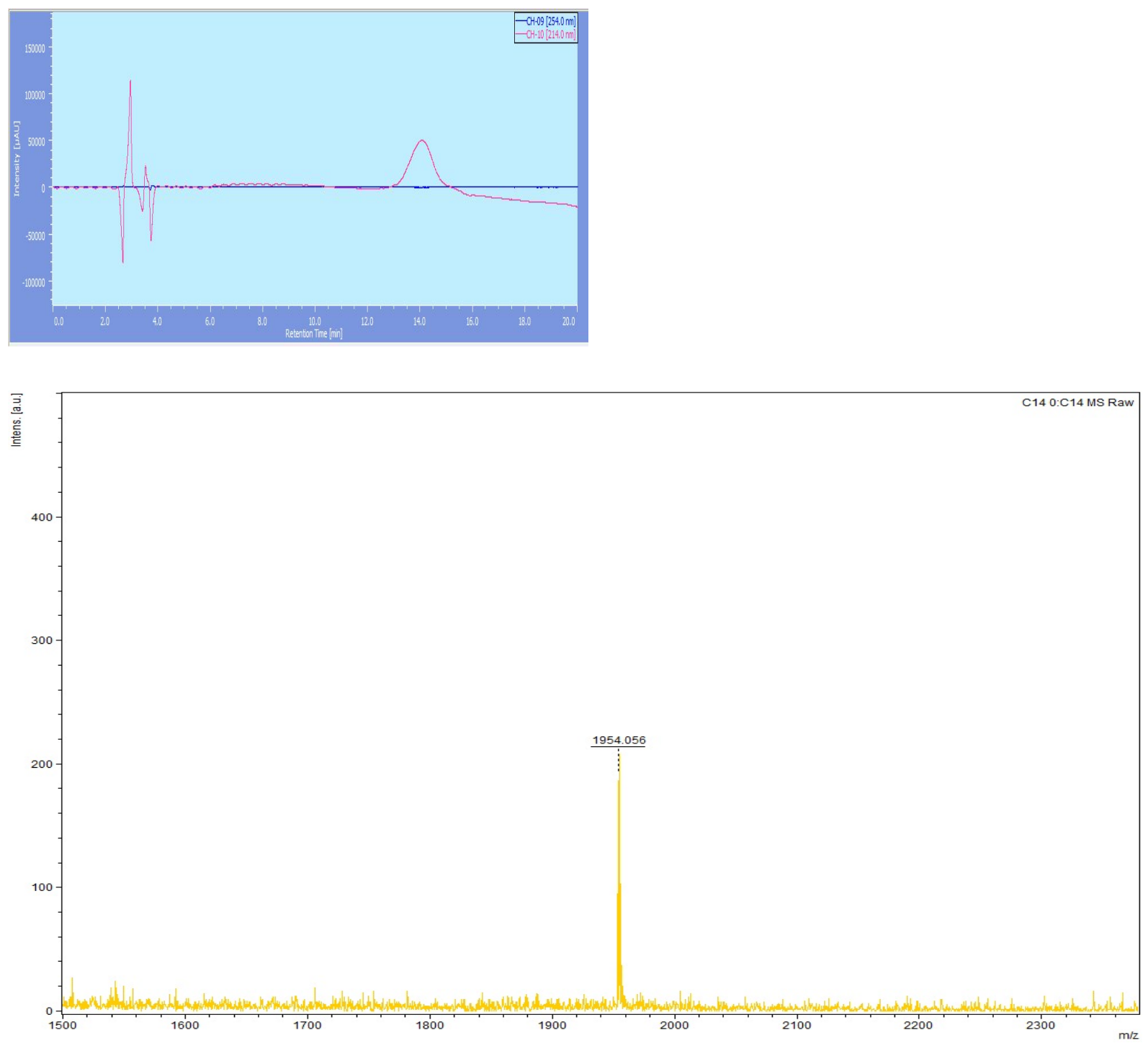
CMP 9 Ac-(Pro-Hyp-Gly) ${ }_{2}$ (Pro-Hyp-azGly)(Pro-Hyp-Gly)(Pro-Hyp-azGly)(Pro-Hyp-Gly) ${ }_{2}-\mathrm{NH}_{2}$

$(\overbrace{0}$

Synthesis: $\mathrm{A}+\mathrm{B}(\mathrm{POG})+\mathrm{B}(\mathrm{POG})+\mathrm{B}$ " $\left(\right.$ FmocNH-NH$\left.{ }_{2}\right)+\mathrm{B}$ "' $(\mathrm{O})+\mathrm{B}$ (P) $+\mathrm{B}(\mathrm{POG})+$ B' $\left(\right.$ FmocNH-NH $\left.{ }_{2}\right)+$ B','(O) + B'(P) + B(POG $)+\mathrm{B}(\mathrm{POG})+\mathrm{C}+\mathrm{D}+\mathrm{E}$

MALDI-MS calculated $[\mathrm{M}+\mathrm{Na}]^{+}$1953.87, found 1954.05
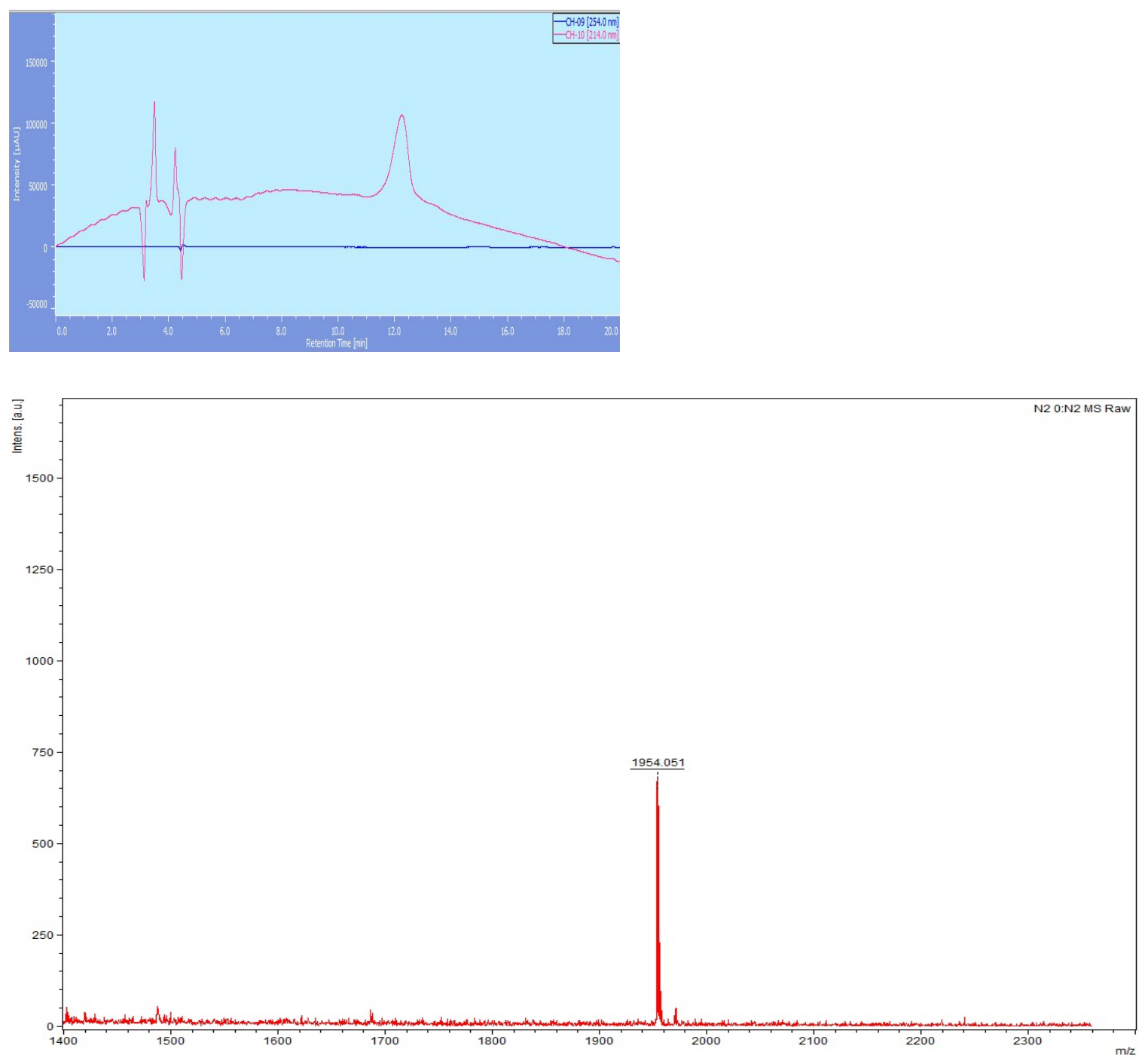
CMP 10 Ac-(Pro-Hyp-Gly) ${ }_{3}$ (Pro-Hyp-azGly) ${ }_{2}\left(\right.$ Pro-Hyp-Gly) ${ }_{2}-\mathrm{NH}_{2}$

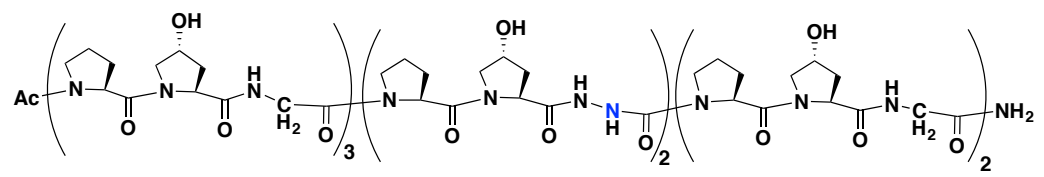

Synthesis: A + B(POG) +B(POG) + B(POG) + B" $($ FmocNH-NH $)+$ B" ' $(\mathrm{O})+$ B' $(\mathrm{P})+$ B" $($ FmocNH-

$\left.\mathrm{NH}_{2}\right)+\mathrm{B}^{\prime \prime}(\mathrm{O})+\mathrm{B}^{\prime}(\mathrm{P})+\mathrm{B}(\mathrm{POG})+\mathrm{B}(\mathrm{POG})+\mathrm{C}+\mathrm{D}+\mathrm{E}$

MALDI-MS calculated $[\mathrm{M}+\mathrm{Na}]^{+} 1953.87$, found 1954.36
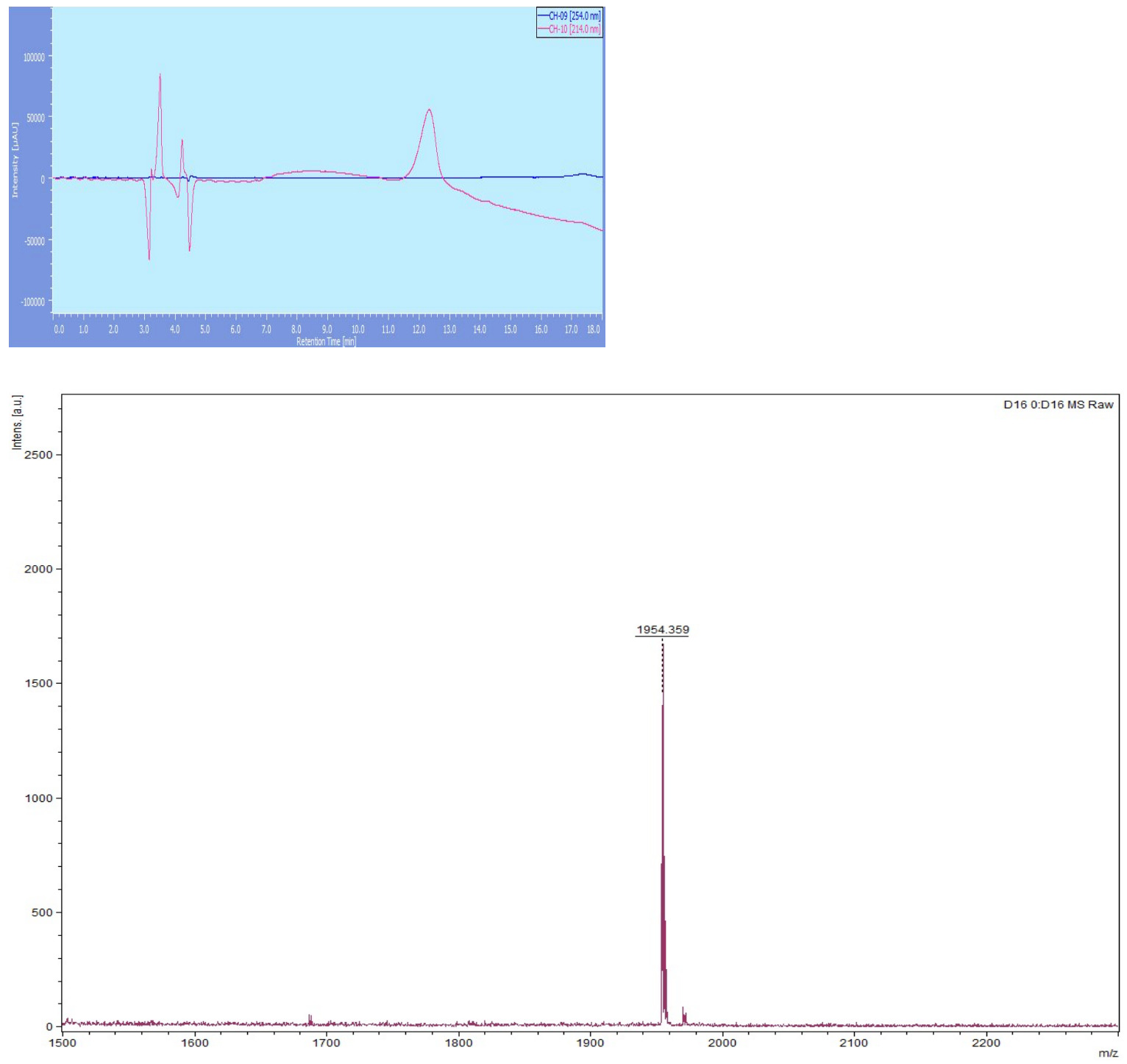
CMP 11 Ac-(Pro-Hyp-Gly)[(Pro-Hyp-azGly)(Pro-Hyp-Gly) $]_{3}-\mathrm{NH}_{2}$

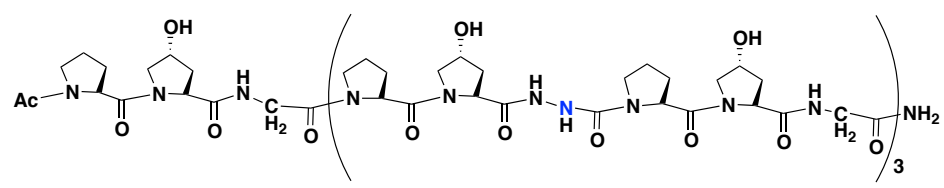

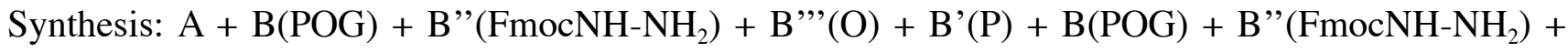
$\mathrm{B}^{\prime \prime \prime}(\mathrm{O})+\mathrm{B},(\mathrm{P})+\mathrm{B}(\mathrm{POG})+\mathrm{B},\left(\mathrm{FmocNH} \mathrm{NH}_{2}\right)+\mathrm{B},{ }^{\prime}(\mathrm{O})+\mathrm{B}^{\prime}(\mathrm{P})+\mathrm{B}(\mathrm{POG})+\mathrm{C}+\mathrm{D}+\mathrm{E}$

MALDI-MS calculated $[\mathrm{M}+\mathrm{Na}]^{+} 1954.87$, found 1955.49
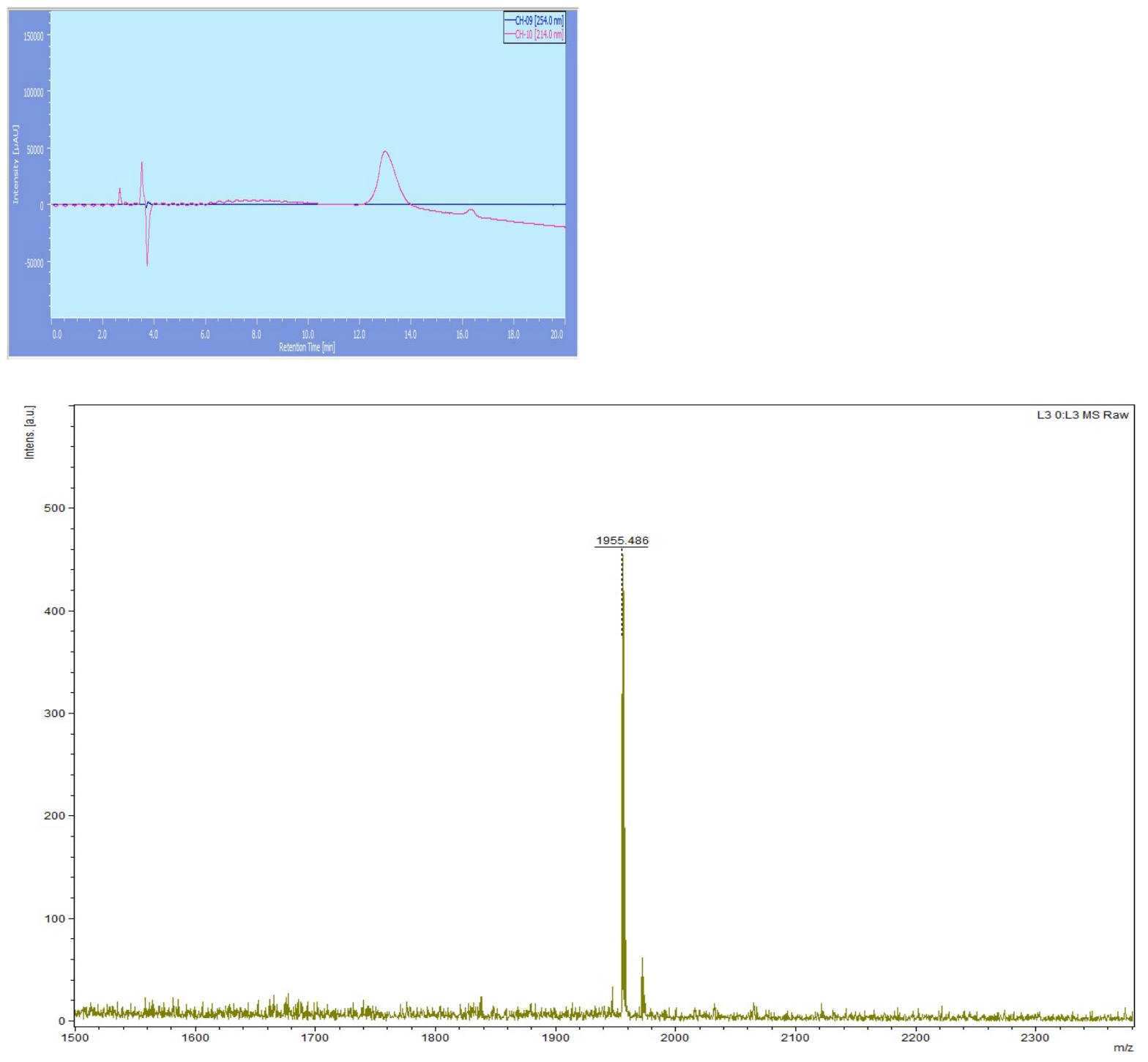
CMP 12 Ac-(Pro-Hyp-Gly) ${ }_{2}$ (Pro-Hyp-azGly) ${ }_{3}\left(\right.$ Pro-Hyp-Gly) ${ }_{2}-\mathrm{NH}_{2}$

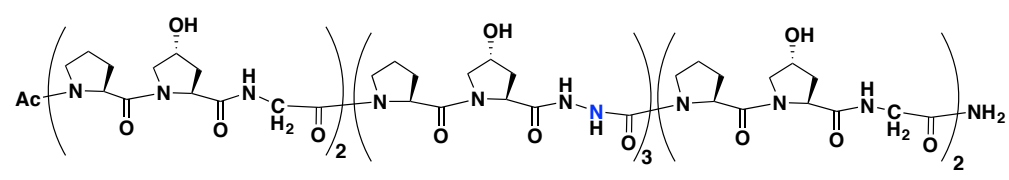

Synthesis: A + B(POG) + B'(G) + B"' (Fmoc-azGPO) + B'"'(Fmoc-azGPO) + B"' (Fmoc-azGPO) + $\mathrm{B}^{\prime \prime}(\mathrm{O})+\mathrm{B} '(\mathrm{P})+\mathrm{B}(\mathrm{POG})+\mathrm{C}+\mathrm{D}+\mathrm{E}$

"Fmoc-azGPO" stands for Fmoc-azGly-Pro-Hyp(tBu)-OH, whose synthesis was described on page S3 and S4.

MALDI-MS calculated $[\mathrm{M}+\mathrm{Na}]^{+}$1954.87, found 1955.34
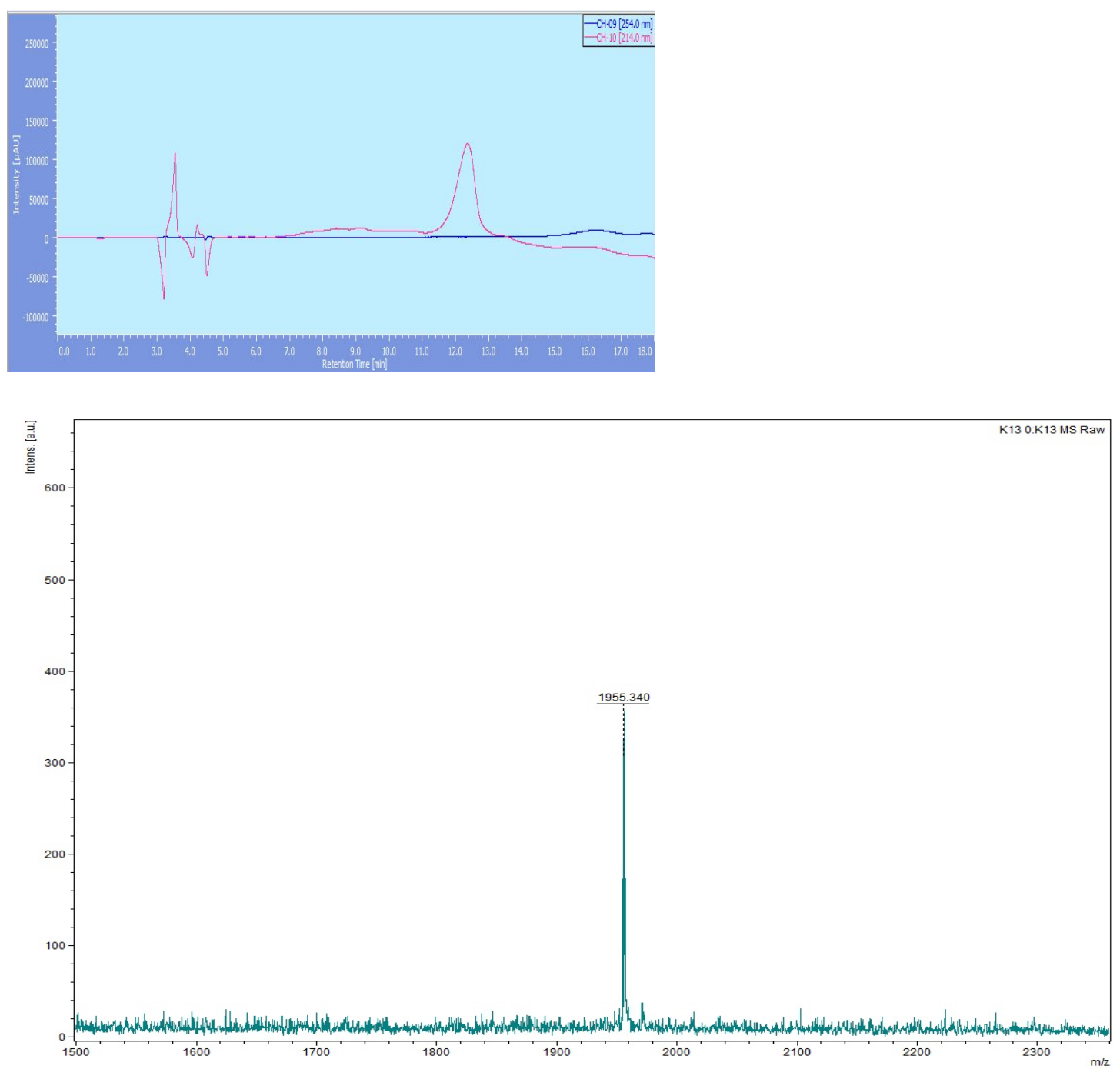
CMP 13 Ac-(azGly-Pro-Hyp) ${ }_{3}-\mathrm{NH}_{2}$

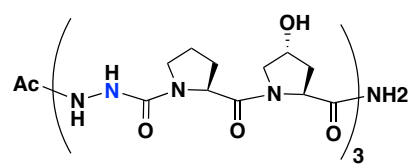

Synthesis: A + B (Fmoc-azGPO $)+$ B"' (Fmoc-azGPO $)+$ B" $($ Fmoc-azGPO $)+$ C + D + E

MALDI-MS calculated $[\mathrm{M}+\mathrm{Na}]^{+}$886.38, found 886.64.
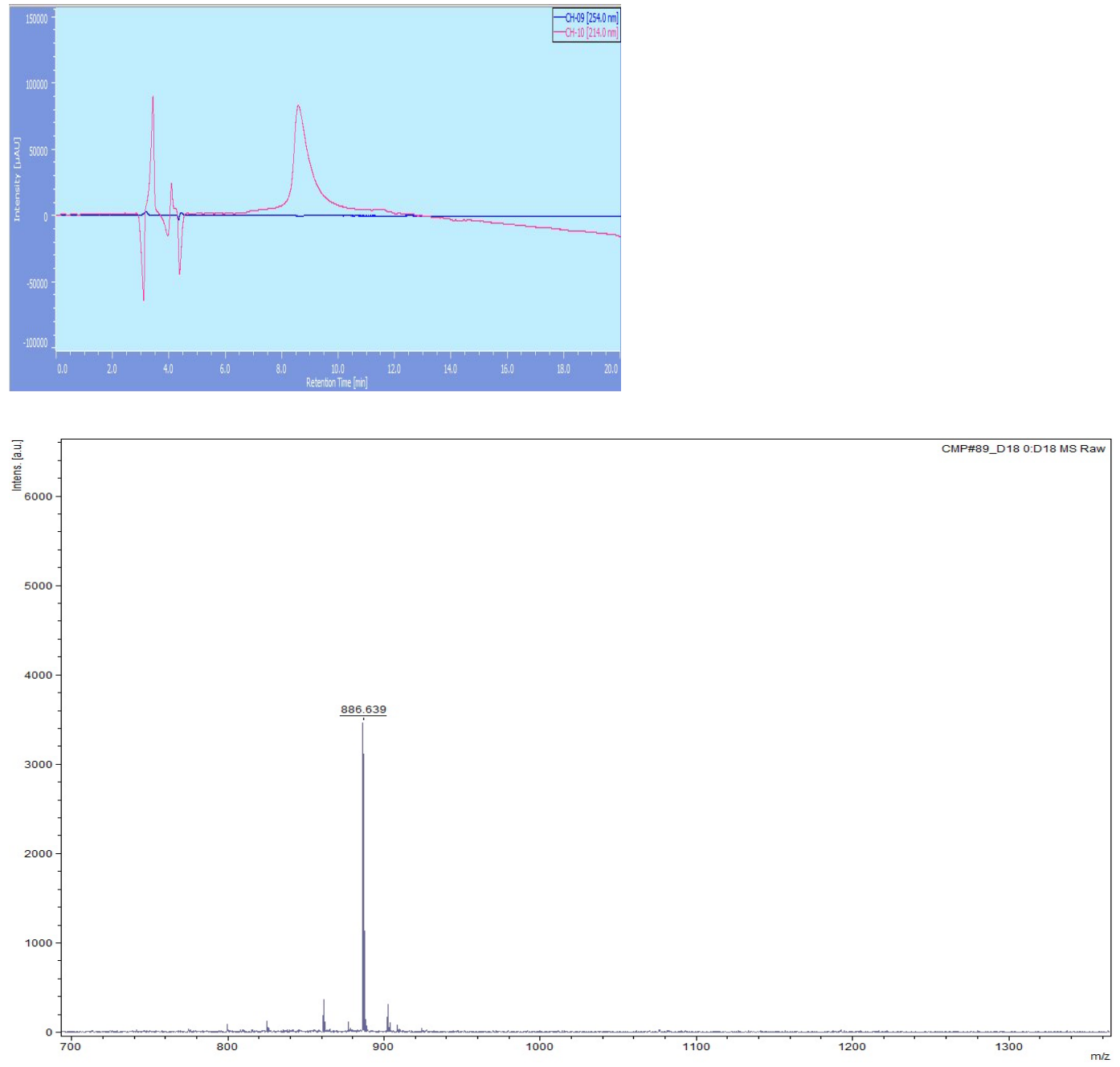
CMP 14 Ac-(azGly-Pro-Hyp) $)_{4}-\mathrm{NH}_{2}$

${ }_{A c}+\overbrace{\mathrm{N}}^{\mathrm{N}}$

Synthesis: A + B(Fmoc-azGPO) + B"'(Fmoc-azGPO $)+$ B"' (Fmoc-azGPO $)+$ B"' (Fmoc-azGPO $)+$ C

$+\mathrm{D}+\mathrm{E}$

MALDI-MS calculated $[\mathrm{M}+\mathrm{Na}]^{+} 1154.50$, found 1153.88
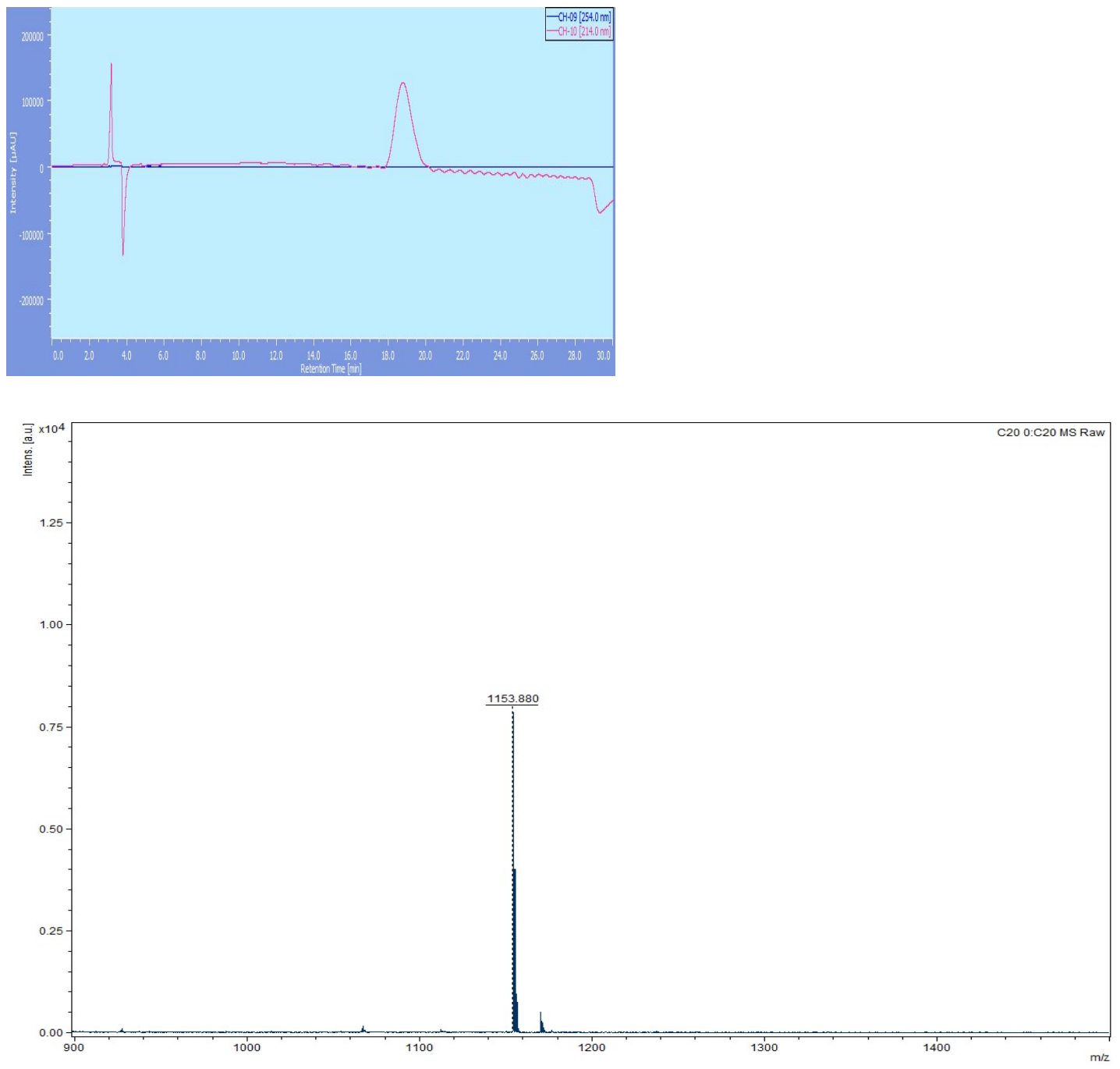
CMP 15 Ac-(azGly-Pro-Hyp) $)_{5}-\mathrm{NH}_{2}$<smiles>CC(C)NNC(=O)N1CCCC1C(=O)N1CC(O)CC1C(=O)NC(C)C</smiles>

Synthesis: A + B(Fmoc-azGPO) + B"' (Fmoc-azGPO) + B"' (Fmoc-azGPO) + B"' (Fmoc-azGPO) + B"' (Fmoc-azGPO $)+C+D+E$

MALDI-MS calculated $[\mathrm{M}+\mathrm{Na}]^{+} 1422.61$, found 1423.44
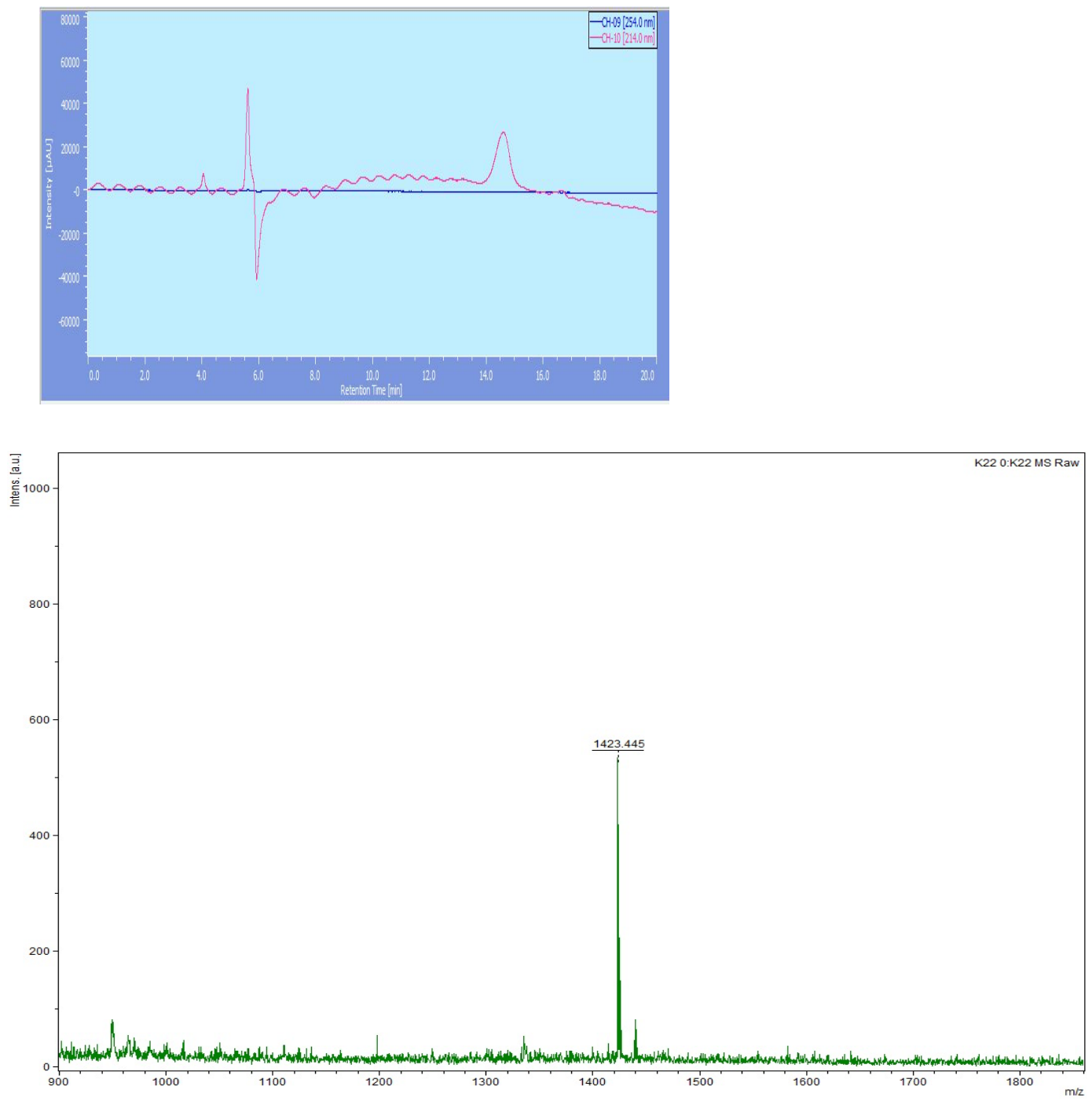


\section{Experiment Protocols}

\section{Peptide sample preparation}

Purified peptides used in this study were made into $0.20 \mathrm{mM}$ solutions in PBS buffer $(0.20 \mathrm{~g} \mathrm{KCl}$, $0.20 \mathrm{~g} \mathrm{KH}_{2} \mathrm{PO}_{4}, 8.0 \mathrm{~g} \mathrm{NaCl}, 2.16 \mathrm{~g} \mathrm{Na}_{2} \mathrm{HPO}_{4} \bullet 7 \mathrm{H}_{2} \mathrm{O}$ in $\left.1.0 \mathrm{~L} \mathrm{H}_{2} \mathrm{O}\right)$. Samples were incubated at 4 ${ }^{0} \mathrm{C}$ for at least $24 \mathrm{~h}$ before $\mathrm{CD}$ experiments.

\section{Wavelength scan}

CD spectra were recorded at a step of $1.0 \mathrm{~nm}$ from $260 \mathrm{~nm}$ to $190 \mathrm{~nm}$ at $10{ }^{0} \mathrm{C}$ with a $1.0 \mathrm{~s}$ equilibration time.

\section{Thermal denaturation experiment}

The wavelength that gave the highest absorption in the range 224-227 $\mathrm{nm}$ was selected and monitored as a function of time in the thermal denaturation experiment. For complete aza-glycine CMPs 13 - 15, the negative absorptions were monitored at five different wavelengths (210 nm, 215 $\mathrm{nm}, 220 \mathrm{~nm}, 225 \mathrm{~nm}, 230 \mathrm{~nm})$. Averaging time was set to be $16 \mathrm{~s}$ with a heating rate of $12{ }^{0} \mathrm{C} / \mathrm{h}$ and the ellipticity of every $1{ }^{0} \mathrm{C}$ was recorded. Data collected from these experiments were fitted to a two-state model according to Engel et al. to obtain the melting temperature (i.e. the temperature at which $50 \%$ of the triple helix unfolds) of each peptide. ${ }^{4}$ We used the software Graphpad Prism 6 and followed the procedure described by Erdmann \& Wennemers. ${ }^{5}$ 


\section{CD kinetic refolding experiment}

Peptide solution of $0.20 \mathrm{mM}$ was heated at $95{ }^{\circ} \mathrm{C}$ for $15 \mathrm{~min}$ and transferred to a CD cuvette (precooled at $4{ }^{\circ} \mathrm{C}$.) After about $1 \mathrm{~min}$, the ellipticity at $224 \mathrm{~nm}$ (for CMP 1), or $215 \mathrm{~nm}$ (for CMP 14 and 15), was monitored at $4{ }^{\circ} \mathrm{C}$ for $3 \mathrm{~h}$, with a $10 \mathrm{~s}$ time constant and $4 \mathrm{~s}$ time interval. The fraction refolded percentage was calculated by the following equation: ${ }^{6}$

$$
\mathrm{F}=\left(\Theta_{\mathrm{T}}-\Theta_{\mathrm{I}}\right) /\left(\Theta_{\mathrm{N}}-\Theta_{\mathrm{I}}\right)
$$

$\mathrm{F}=$ fraction refolded; $\Theta_{\mathrm{T}}=$ ellipticity at time t; $\Theta_{\mathrm{N}}=$ ellipticity before denaturation; $\Theta_{\mathrm{I}}=$ first data (initial) recorded after $\sim 65 \mathrm{~s}$ cooling (dead time). Plots of fraction refolded data versus time (minutes as units) were then fitted into a $3^{\text {rd }}$ order kinetic equation as previously reported. ${ }^{7}$ Halfrefolding time $\left(t_{1 / 2}\right)$ was then obtained as the time value at which $50 \%$ of each peptide recovered triple helicity. At least 3 kinetic refolding curves were collected and fitted for each peptide in this study. 


\section{Spectra}

CD plots for CMP 3 Ac-(Pro-Hyp-azGly)(Pro-Hyp-Gly) ${ }_{6}-\mathrm{NH}_{2}$

Left: CD wavelength scan; Right: CD thermal denaturation experiment;
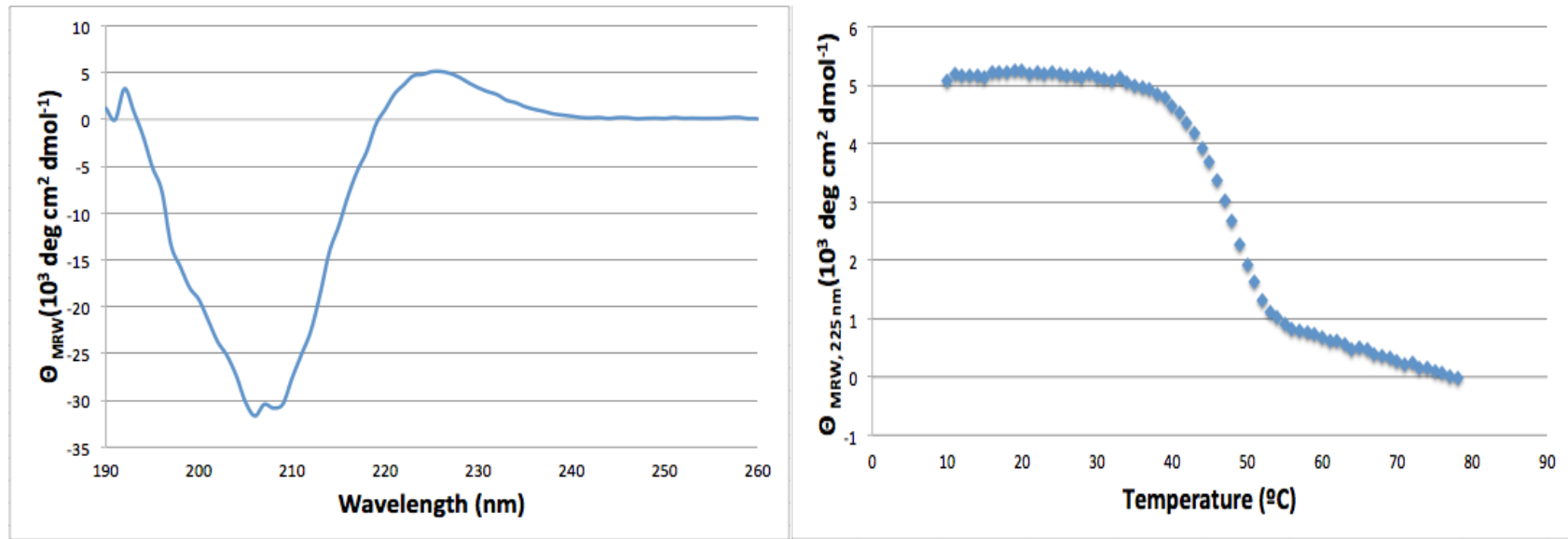

CD plots for CMP 4 Ac-(Pro-Hyp-Gly)(Pro-Hyp-azGly)(Pro-Hyp-Gly) ${ }_{5}-\mathrm{NH}_{2}$

Left: CD wavelength scan; Right: CD thermal denaturation experiment;
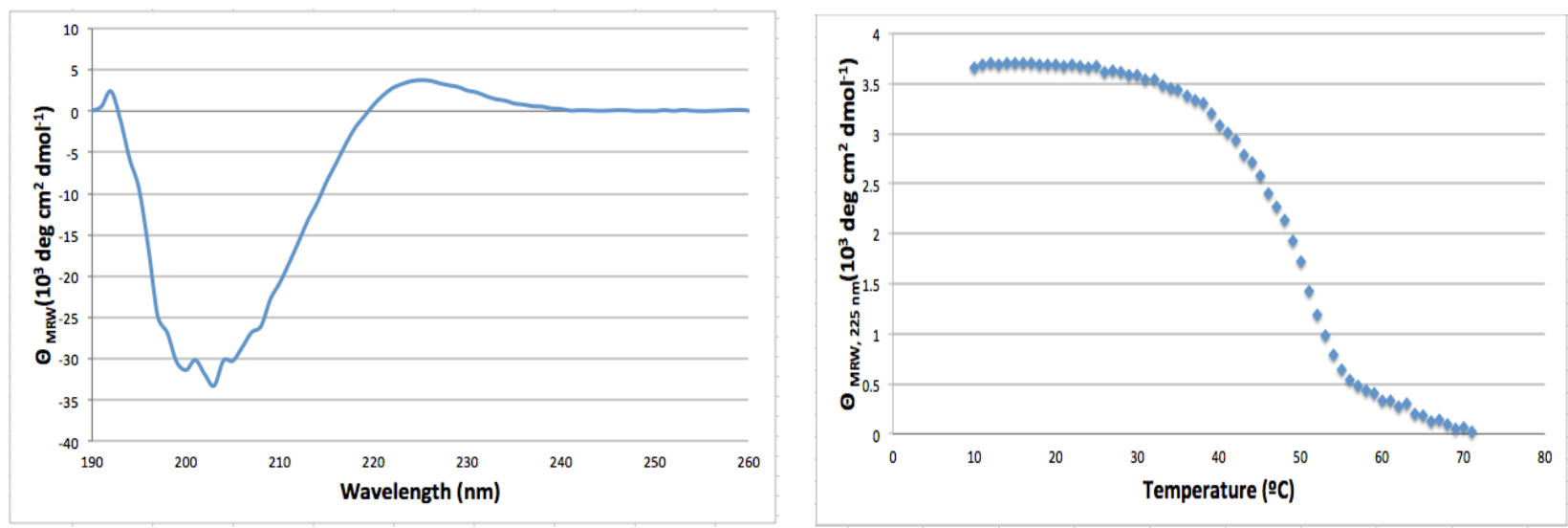
CD plots for CMP 5 Ac-(Pro-Hyp-Gly) ${ }_{2}$ (Pro-Hyp-azGly)(Pro-Hyp-Gly) ${ }_{4}-\mathrm{NH}_{2}$

Left: CD wavelength scan; Right: CD thermal denaturation experiment;
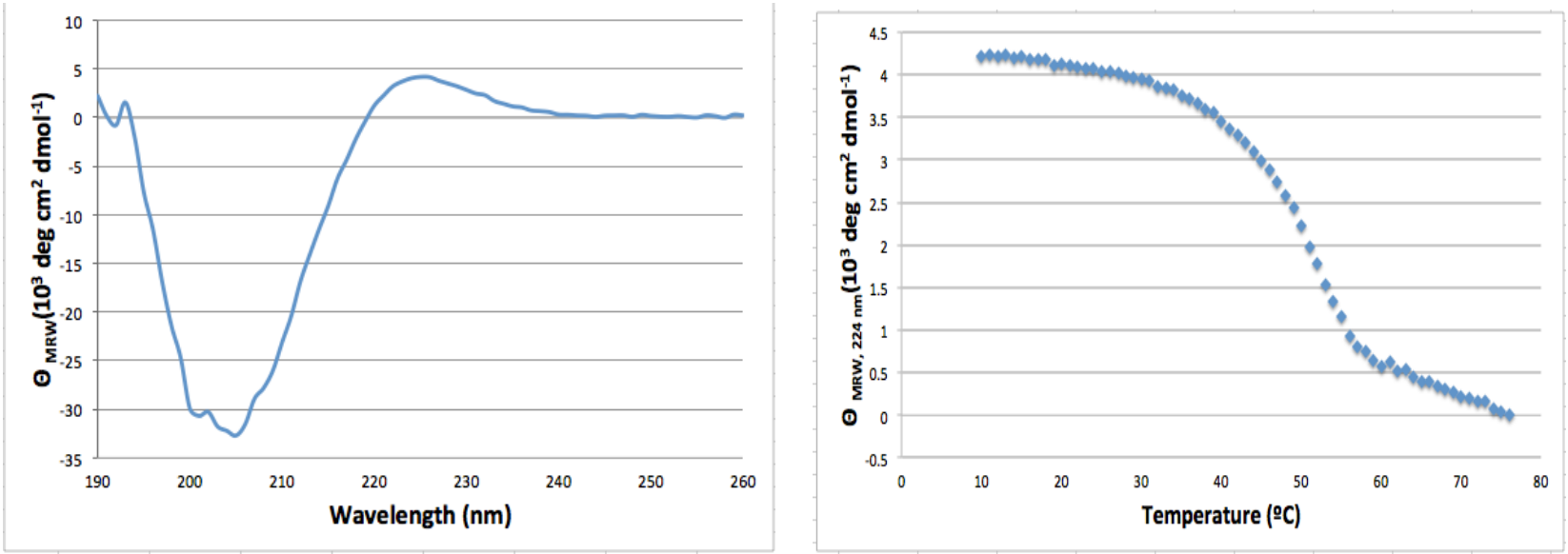

CD plots for CMP 6 Ac-(Pro-Hyp-Gly) ${ }_{4}\left(\right.$ Pro-Hyp-azGly)(Pro-Hyp-Gly) ${ }_{2}-\mathrm{NH}_{2}$

Left: CD wavelength scan; Right: CD thermal denaturation experiment;
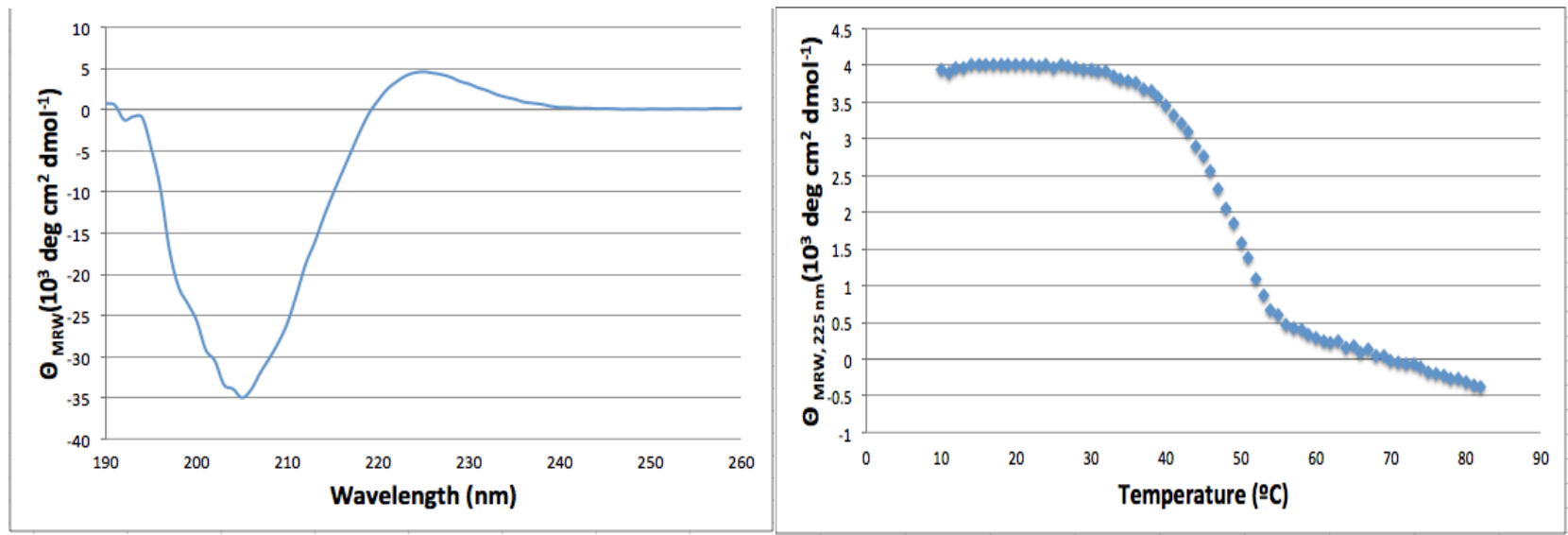
CD plots for CMP 7 Ac-(Pro-Hyp-Gly) ${ }_{5}$ (Pro-Hyp-azGly)(Pro-Hyp-Gly)- $\mathrm{NH}_{2}$

Left: CD wavelength scan; Right: CD thermal denaturation experiment;
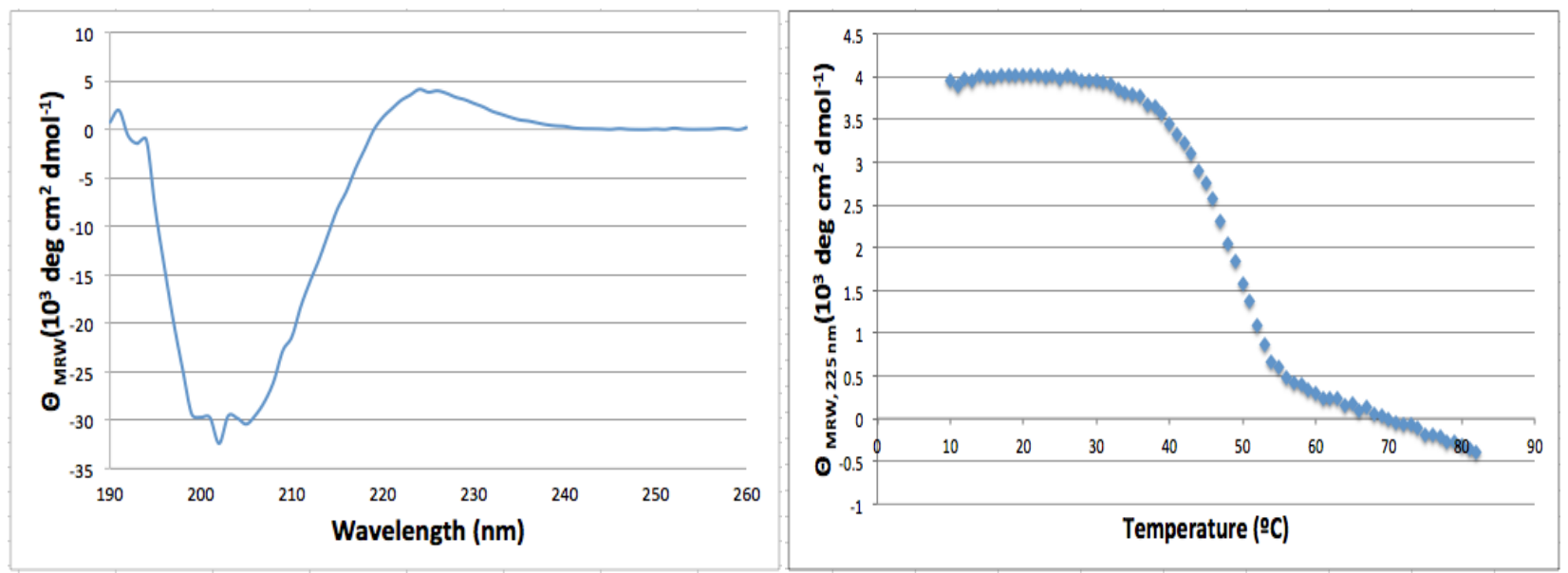

CD plots for CMP 8 Ac-(Pro-Hyp-Gly)(Pro-Hyp-azGly)(Pro-Hyp-Gly) ${ }_{3}($ Pro-Hyp-azGly)(Pro-Hyp-Gly)-NH 2

Left: CD wavelength scan; Right: CD thermal denaturation experiment;
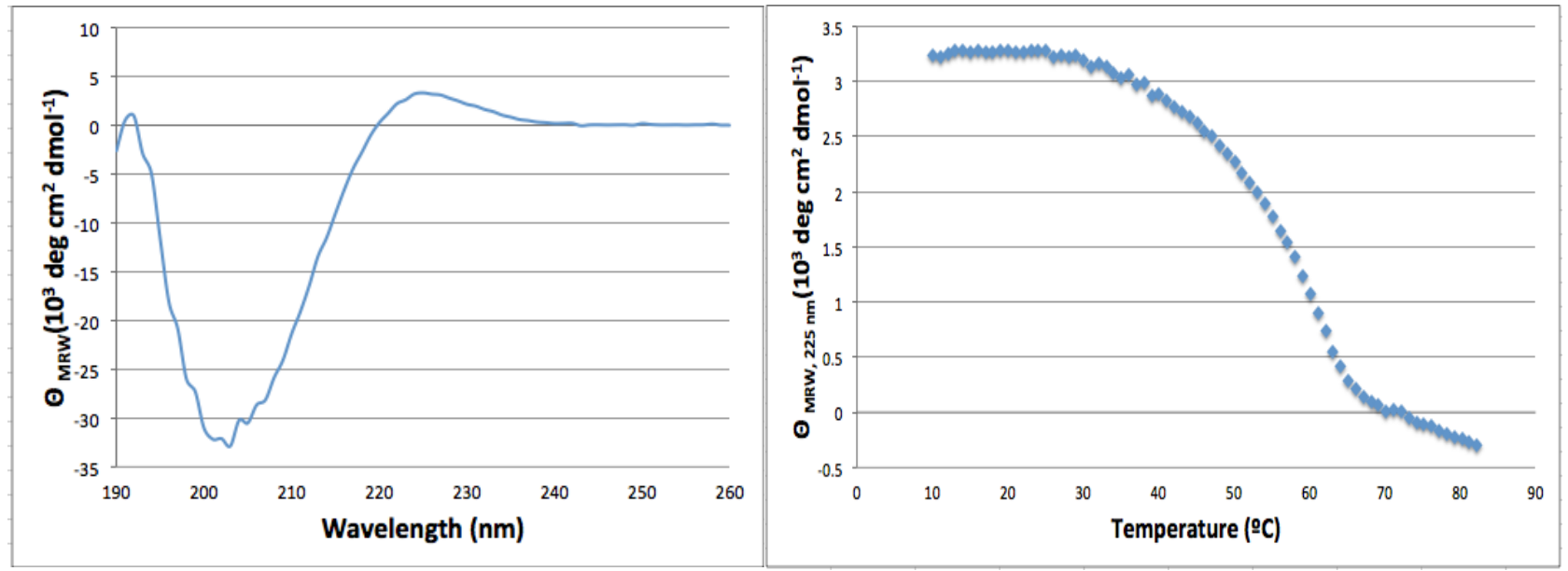
CD plots for CMP 9 Ac-(Pro-Hyp-Gly) ${ }_{2}$ (Pro-Hyp-azGly)(Pro-Hyp-Gly)(Pro-Hyp-azGly)(Pro-HypGly) $)_{2}-\mathrm{NH}_{2}$

Left: CD wavelength scan; Right: CD thermal denaturation experiment;

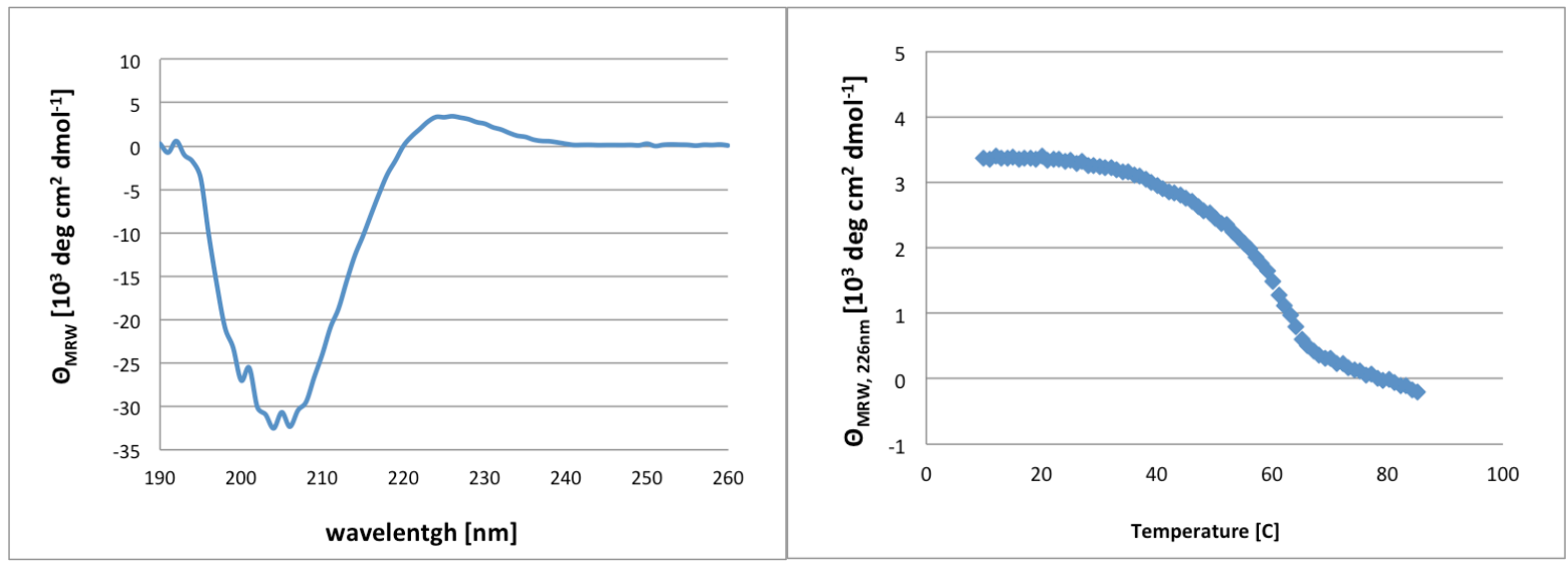

\section{CD plots for CMP 10 Ac-(Pro-Hyp-Gly $)_{3}(\text { Pro-Hyp-azGly })_{2}(\text { Pro-Hyp-Gly })_{2}-\mathrm{NH}_{2}$}

Left: CD wavelength scan; Right: CD thermal denaturation experiment;
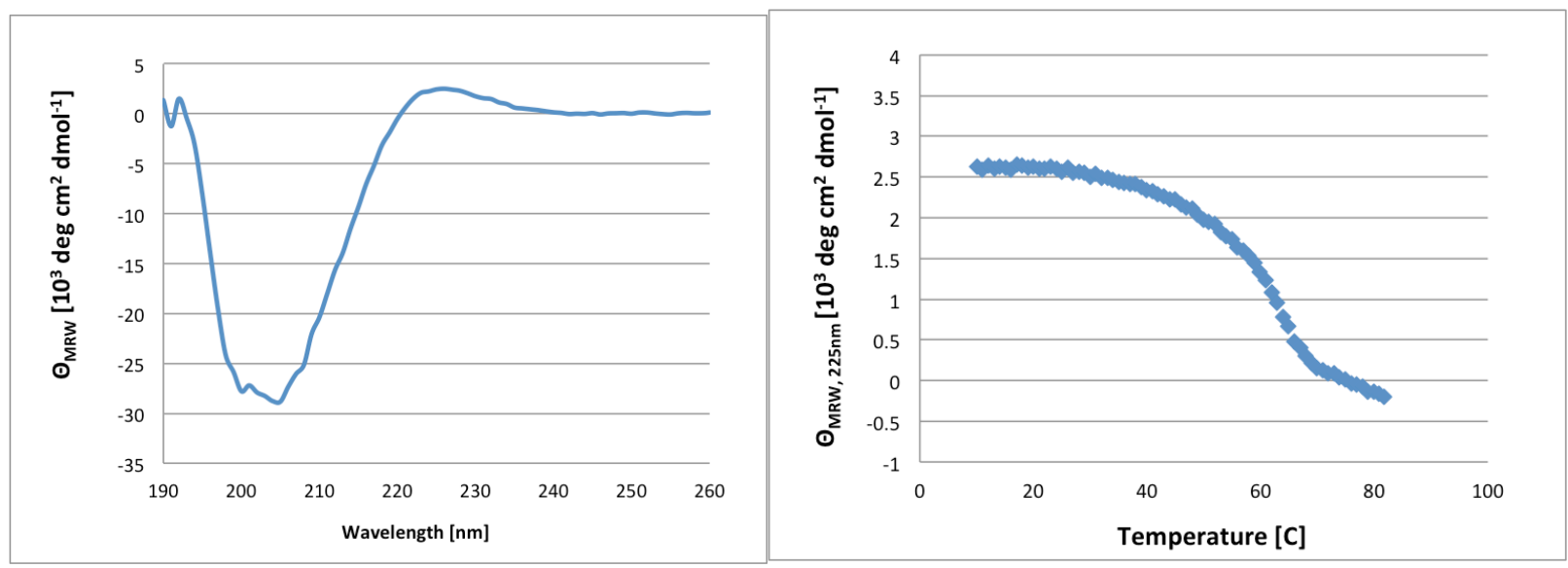
CD plots for CMP 11 Ac-(Pro-Hyp-Gly)[(Pro-Hyp-azGly)(Pro-Hyp-Gly) $]_{3}-\mathrm{NH}_{2}$

Left: CD wavelength scan; Right: CD thermal denaturation experiment;
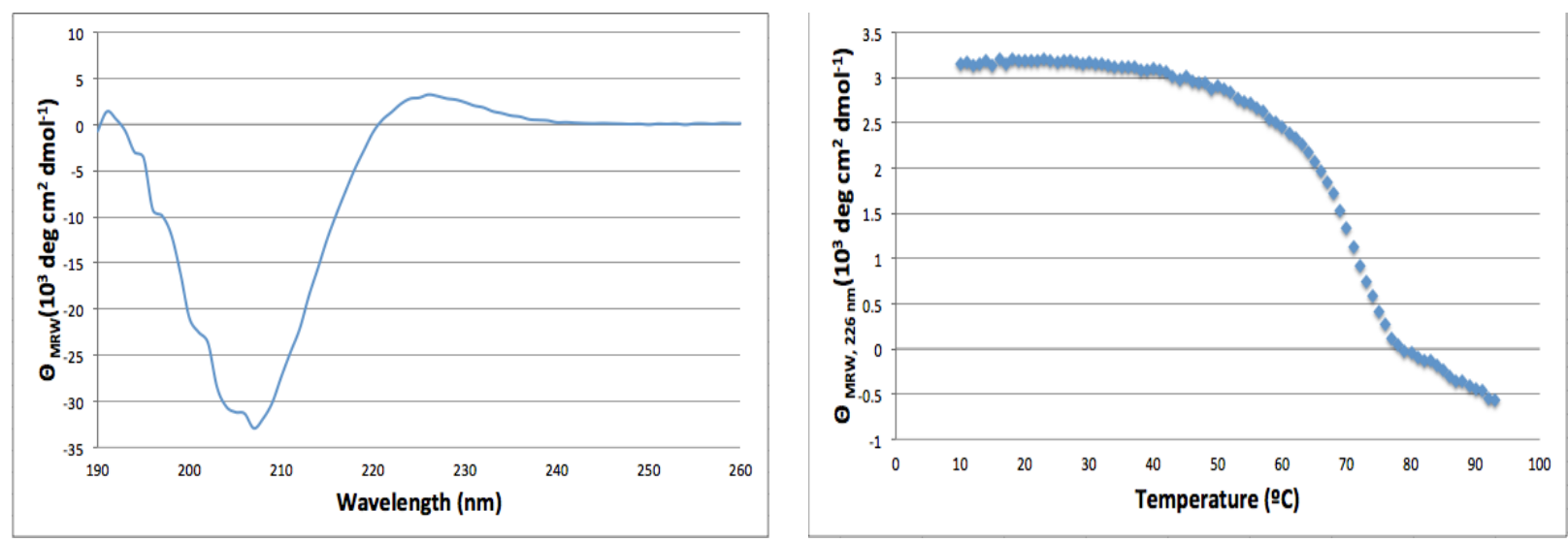

\section{CD plots for CMP 12 Ac-(Pro-Hyp-Gly) ${ }_{2}$ (Pro-Hyp-azGly) $)_{3}$ (Pro-Hyp-Gly) ${ }_{2}-\mathrm{NH}_{2}$}

Left: CD wavelength scan; Right: CD thermal denaturation experiment;
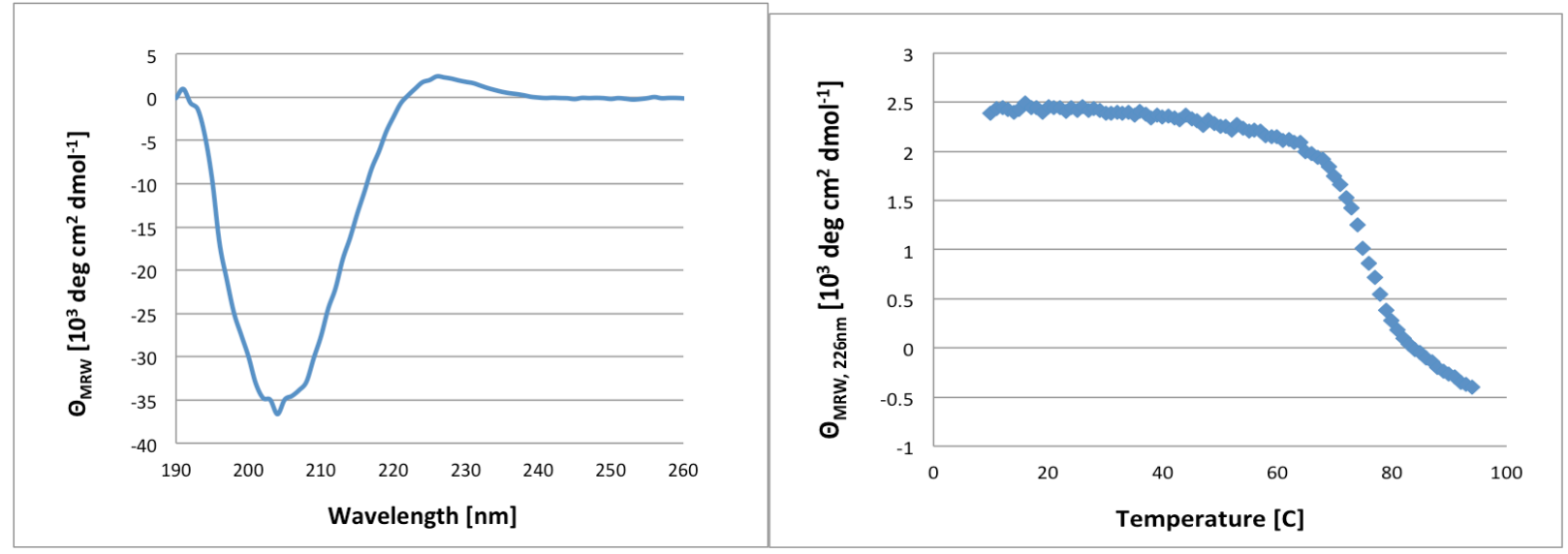
Summary of $\lambda_{\max }$ and CD Ellipticity at $\lambda_{\max }$ for CMP 1-12

\begin{tabular}{|c|c|c|}
\hline CMP & $\lambda_{\max } / \mathrm{nm}$ & CD Elipticity at $\lambda_{\max } / \mathrm{mdeg}$ \\
\hline $\mathbf{1}$ & 224 & 18.9 \\
\hline $\mathbf{2}$ & 225 & 15.7 \\
\hline $\mathbf{3}$ & 225 & 21.4 \\
\hline $\mathbf{4}$ & 225 & 15.7 \\
\hline $\mathbf{5}$ & 225 & 17.5 \\
\hline $\mathbf{6}$ & 225 & 19.1 \\
\hline $\mathbf{7}$ & 225 & 16.7 \\
\hline $\mathbf{8}$ & 225 & 13.9 \\
\hline $\mathbf{9}$ & 226 & 14.3 \\
\hline $\mathbf{1 0}$ & 225 & 11.1 \\
\hline $\mathbf{1 1}$ & 226 & 13.5 \\
\hline $\mathbf{1 2}$ & 227 & 8.5 \\
\hline
\end{tabular}

\section{UV-Vis spectrum of CMP 13-15}

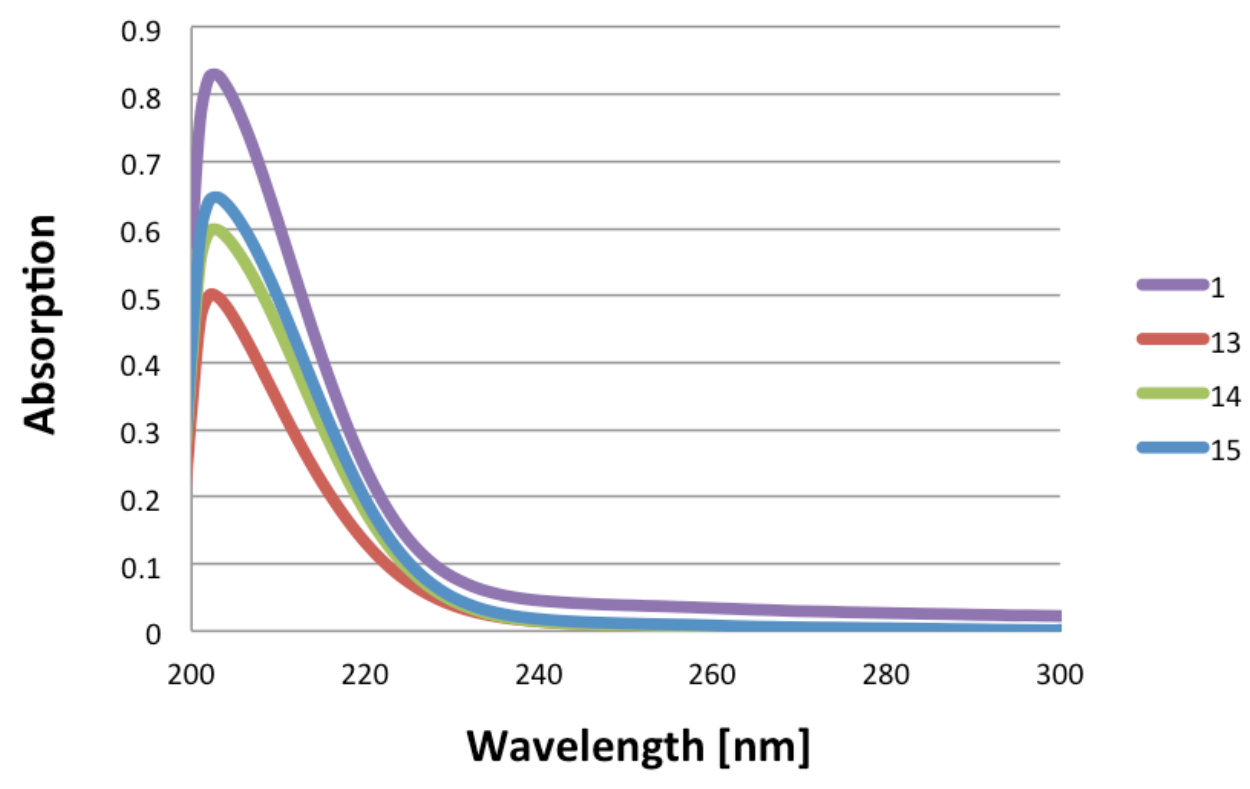

Figure S3. UV-Vis spectra of CMP 13-15 and control peptide 1, Ac(POG) $)_{7} \mathrm{NH}_{2}$. 


\section{CD scan of CMP 13-15}
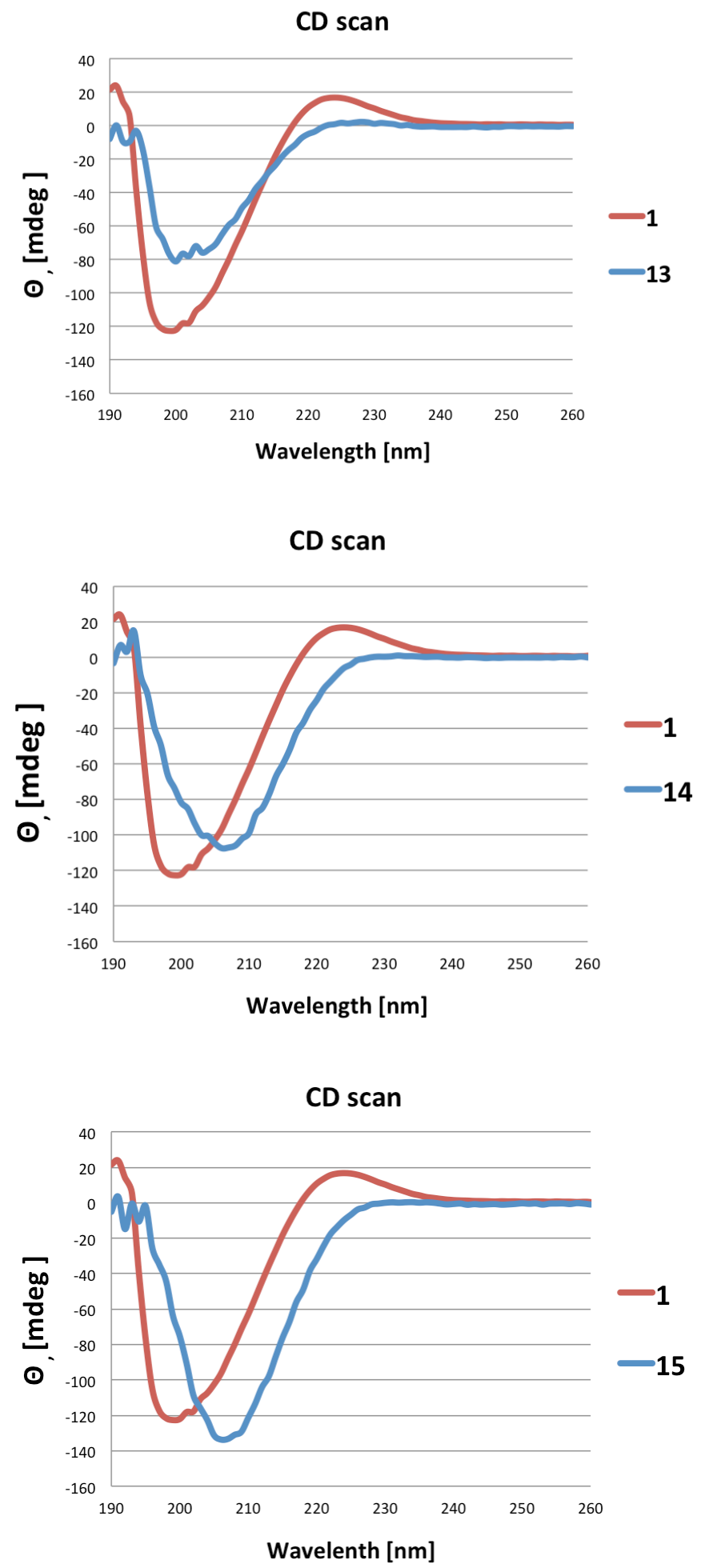

Figure S4. CD spectrum of CMP 13-15 with red curve from natural control peptide 1, $\mathrm{Ac}(\mathrm{POG})_{7} \mathrm{NH}_{2}$ 


\section{Temperature-dependent CD experiments for CMP 13-15 and 1.}
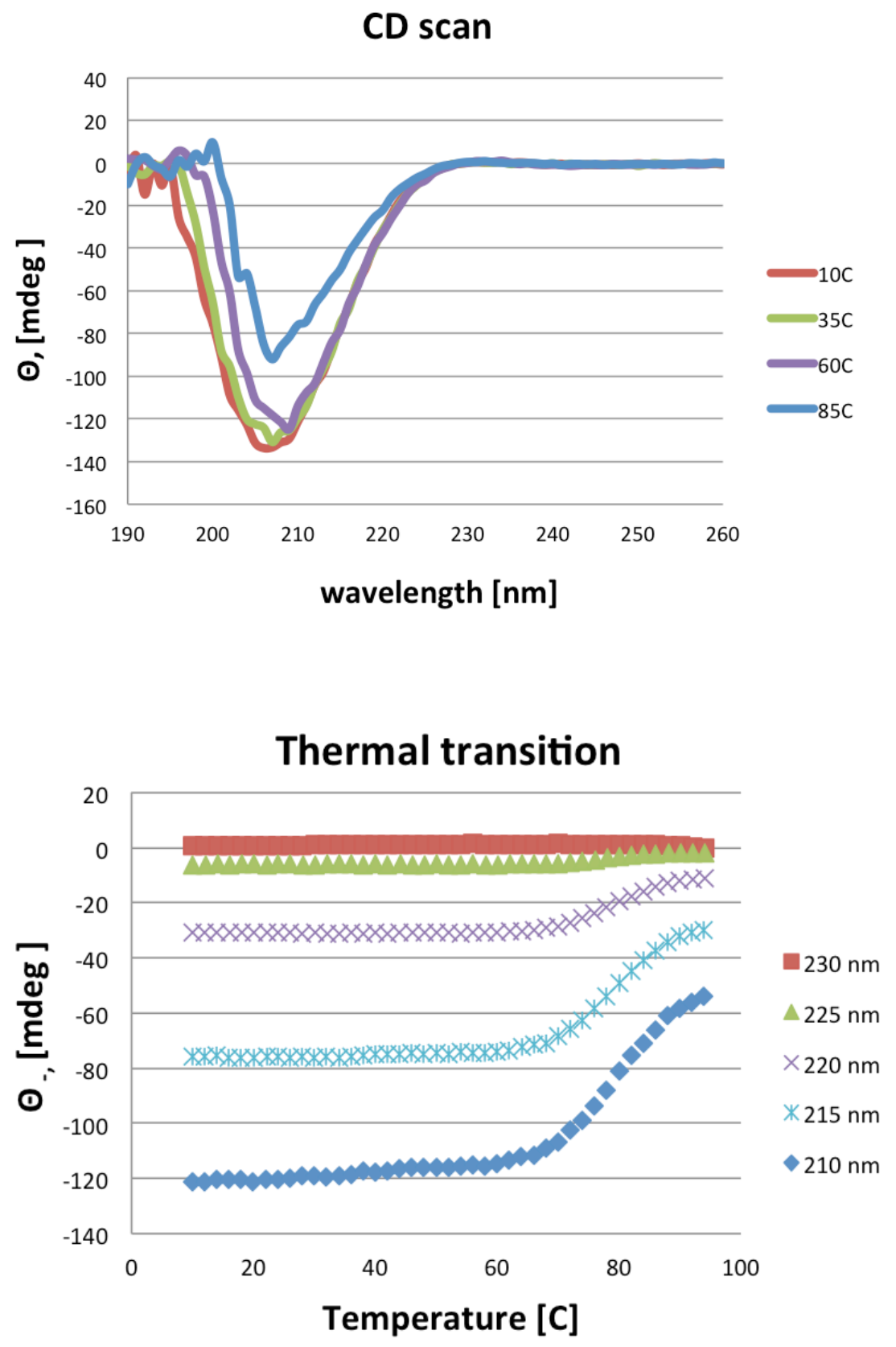

Figure S5. Variable temperature CD scan and thermal transition plots (multiple wavelength channels) for CMP 15 Ac-(azGly-Pro-Hyp) $)_{5}-\mathrm{NH}_{2}$. 

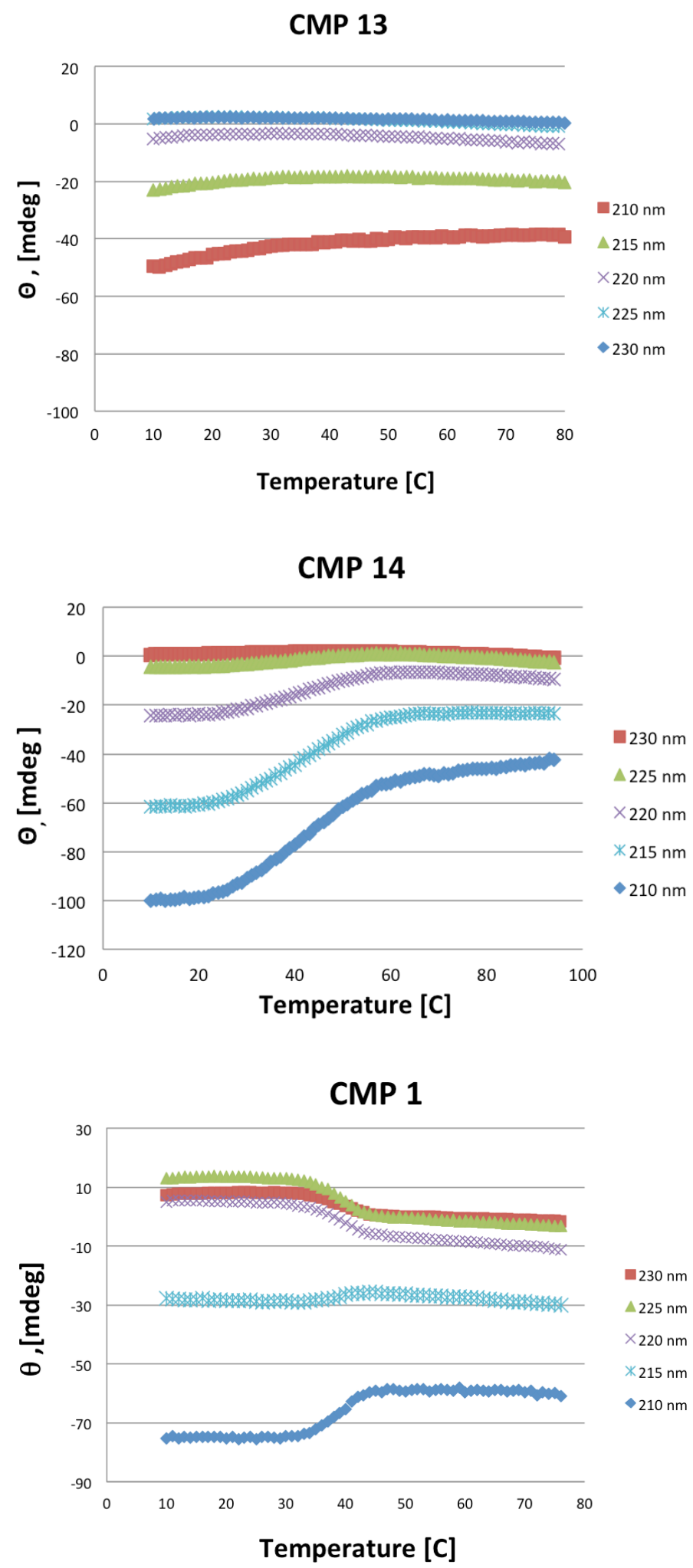

Figure S6. CD thermal transition plots (multiple wavelength channels) for CMP 13, 14, and control peptide 1. 


\section{References}

1. Technical note: Determination of the Amino Acid Substitution Level via an Fmoc Assay, http://www3.appliedbiosystems.com/cms/groups/psm_marketing/documents/generaldocument s/cms_040640.pdf

2. Carpino, L. A.; Han, G. Y. J. Org. Chem. 1972, 37, 3404-3409.

3. Sacca, B.; Moroder, L. J. Peptide Sci.2002, 8, 192-204.

4. Engel, J.; Chen, H. T.; Prockop, D. J.; Klump, H. Biopolymers 1977, 16, 601-622.

5. Erdmann, R. S.; Wennemers, H. Angew. Chem., Int. Ed. 2011, 50, 6835-6838.

6. Kotch, F. W.; Raines, R. T.Proc. Natl. Acad. Sci. U.S.A. 2006, 103, 3028-3033

7. Greenfield, N. J. Nat. Protoc.2006, 1, 2891-2899. 
Appendix 1: SEC-MALS Report

\section{HPLC Size Exclusion Chromatography/ Laser Light Scattering Determination of Native Protein Molecular Weights}

From: Ewa Folta-Stogniew

HHMI Biopolymer Facility and

W.M. Keck Foundation Biotechnology Resource Laboratory

300 George Street, PO box 201

New Haven CT 06511

Telephone: (203) 737-4387 Fax: (203) 785-7023

Email: Ewa.Folta-Stogniew@yale.edu

File directory: ASTRA/Jun_16

Column: Superdex peptide $\# 2$, HR 10/300

Buffer: PBS+azide from 10x stock

Each sample was filtered through $20 \mathrm{~nm}$ Anotop filters before analysis. Samples were analyzed at $200 \mathrm{ul}$ and $50 \mathrm{ul}$ injection from filtered samples.

During sample analysis, the MW is determined by solving the equation that relates the excess scattered light, measured at several angles, to the concentration of solute and the weight-average molar mass (ASTRA calculations, please refer to

"http://info.med.yale.edu/wmkeck/6_16_98/Astra2a.htm\#Calculation of MW by" _for details on the ASTRA calculations). During data analysis a $\mathrm{dn} / \mathrm{dc}$ value of $0.188 \mathrm{~mL} / \mathrm{g}$ was used as it proved satisfactory during analyses of protein standards in PBS.

The UV traces were recorded at $220 \mathrm{~nm}$ and $235 \mathrm{~nm}$ (to prevent saturation of the signal).

\section{Sample Names:}

CMP 14 in manuscript $=$ CMP-87 in SEC-MALS report: Ac- $(\text { azGPO })_{4}-\mathrm{NH}_{2}$

CMP 15 in manuscript $=$ CMP-88 in SEC-MALS report: Ac- $(\text { azGPO })_{5}-\mathrm{NH}_{2}$

Single strand peptide controls used for analysis:

CMP 90 represents a single strand control for CMP 14. The structure of CMP 90 is:

Ac- $(\mathrm{POG})_{4}-\mathrm{NH}_{2}$

CMP 91 represents a single strand control for CMP 15. The structure of CMP 91 is:

Ac- $(\mathrm{POG})_{5}-\mathrm{NH}_{2}$ 
Table 1. Results of SEC-LS/RI/UV analysis from ASTRA (reports for major peaks of selected analyses).

\begin{tabular}{|c|c|c|c|c|c|}
\hline RUN & $\begin{array}{l}\text { PEAK } \\
\text { Elution } \\
\text { at } \mathrm{RI} \\
\text { trace }(\mathrm{mL})\end{array}$ & $\begin{array}{c}\text { MW } \\
\text { Average of } \\
\text { eluting peak } \\
\text { (Da) }\end{array}$ & $\begin{array}{l}\text { Molar mass } \\
\text { range across } \\
\text { eluting peak }\end{array}$ & $\begin{array}{l}\text { Sequence } \\
\text { Predicated } \\
\text { MW for } \\
\text { monomer } \\
\text { (kDa) }\end{array}$ & Comments \\
\hline \#87_200ul & 11.11 & 3271 & $3150-3300$ & 1132 & \\
\hline \#88_200ul & 10.56 & 4149 & $4050-4150$ & 1400 & \\
\hline \#90_200ul & 12.76 & 1098 & $1070-1100$ & 1128 & \\
\hline \#91_200ul & 12.03 & 1388 & $1350-1400$ & 1395 & \\
\hline \multicolumn{6}{|c|}{$\begin{array}{l}\text { A monodisperse peak is a peak that appears to contain only one type of molecule (e.g., pure monomeric protein) and } \\
\text { results in one apparent MW. Thus the average mass is independent of the averaging method and the polydispersity (see ASTRA } \\
\text { Summary Report) will equal } 1 \text {. If the peak contains a mixture of species of different molar masses (i.e., polydisperse peak; for } \\
\text { example, a mixture of dimer (or tetramer) and monomer) the average mass will depend on the averaging method and the } \\
\text { polydispersity will be different then } 1 .\end{array}$} \\
\hline $\begin{array}{l}\text { a as sho } \\
\text { **N/D not dete } \\
\text { determinatic }\end{array}$ & $\begin{array}{l}\text { Mass Distributi } \\
\text { he signal was } \\
\text { gersity }\end{array}$ & ne of the eluti & contained 50 & oteins preclu & liable \\
\hline
\end{tabular}

The distribution of molar masses across the eluting peak are shown below:

Solid lines: traces from UV recorded at $235 \mathrm{~nm}$; dots: MW measured every $2 \mathrm{~s}$ across the eluting peak.

molar mass vs. volume

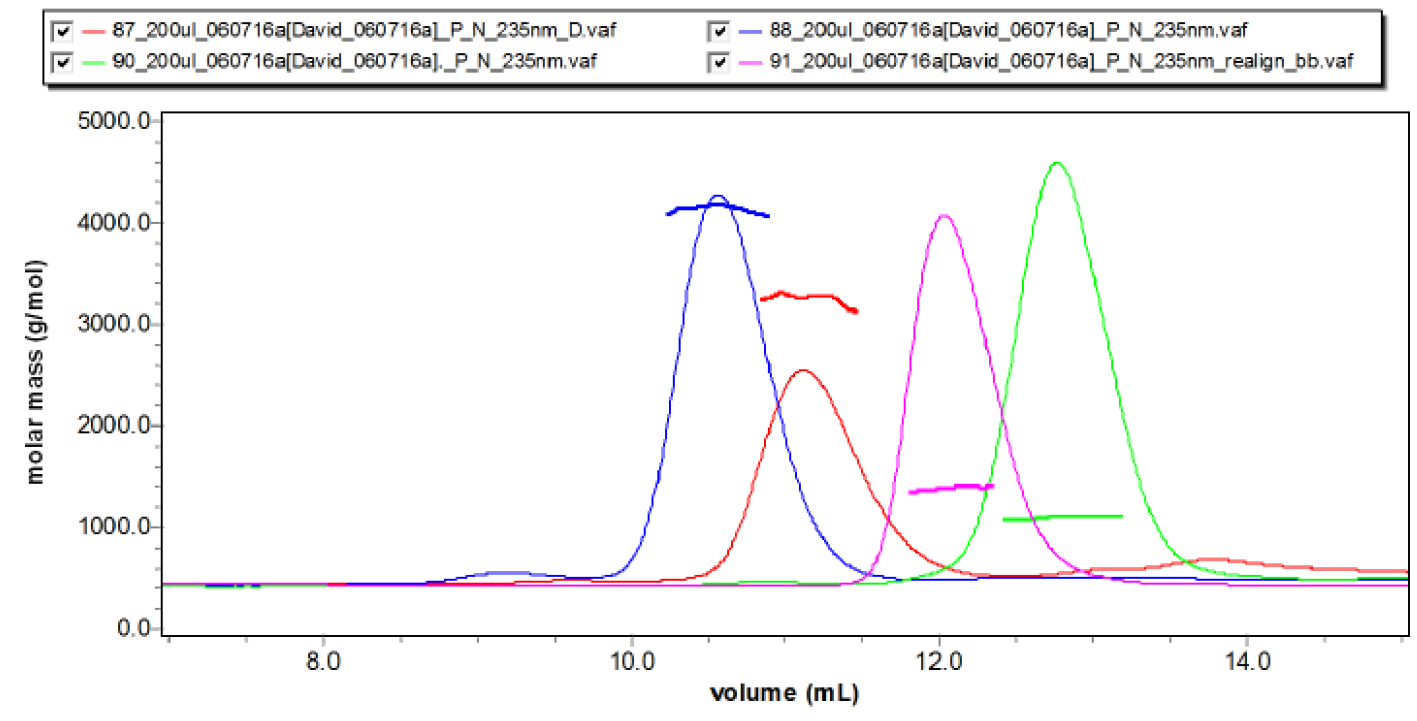

Summary Table:

\begin{tabular}{|l|r|r|r|l|r|}
\hline SAMPLE & \multicolumn{1}{|c|}{ monomer } & trimer & observed & oligomer & differential \\
\hline CMP-87 & 1132 & 3250 & 3271 & trimer & $0.6 \%$ \\
\hline CMP88 & 1400 & 4200 & 4149 & trimer & $1.2 \%$ \\
\hline CMP90 & 1128 & 3384 & 1098 & monomer & $2.7 \%$ \\
\hline CMP91 & 1395 & 4185 & 1388 & monomer & $0.5 \%$ \\
\hline
\end{tabular}


Appendix 2: Analytical Ultracentrifugation Report: Contained on following pages 


\section{Sample \& Method}

\section{Contact Person}

David M. Chenoweth, Ph.D.

Department of Chemistry

University of Pennsylvania

231 S. 34 Street, Philadelphia, PA 19104-6323

\section{Sample}

Two protein samples, CMP\#87 and CMP\#88, were submitted for analysis by sedimentation equilibrium (SE) ultracentrifugation. Each sample was supplied at $1 \mathrm{mg} / \mathrm{ml}$. A $15 \mathrm{~mL}$ sample of the buffer was also supplied.

\section{Buffer}

PBS $(0.20 \mathrm{~g} \mathrm{KCl}, 0.20 \mathrm{~g} \mathrm{KH} 2 \mathrm{PO} 4,8.0 \mathrm{~g} \mathrm{NaCl}, 2.16 \mathrm{~g} \mathrm{Na} 2 \mathrm{HPO} 4 \bullet 7 \mathrm{H} 2 \mathrm{O}$ in $1.0 \mathrm{~L} \mathrm{H} 2 \mathrm{O})$.

\section{Physical Constants}

The following physical constants were calculated from the amino acid composition for the proteins using the program Sednterp. ${ }^{5}$ The calculated $\bar{v}_{20^{\circ}}$ are only a close approximation as there is no way to estimate the effect on the partial specific volume of the protein due to the presence of the "az" moieties.

$$
\begin{array}{ll}
\mathrm{CMP} \# 87-\mathrm{Ac}\left(\text { azGPO) }{ }_{4} \mathrm{NH}_{2}:\right. & \mathrm{MW}_{\text {seq }}=1132 \mathrm{Da}, \bar{v}_{20^{\circ}}=0.695 \mathrm{ml} / \mathrm{g} \\
\mathrm{CMP} \# 88-\mathrm{Ac}\left(\text { azGPO) }{ }_{5} \mathrm{NH}_{2}:\right. & \mathrm{MW}_{\text {seq }}=1400 \mathrm{Da}, \bar{v}_{20^{\circ}}=0.696 \mathrm{ml} / \mathrm{g}
\end{array}
$$

The buffer density and viscosity were calculated to be $1.00533 \mathrm{~g} / \mathrm{mL}$ and 0.01019 poise at $20^{\circ} \mathrm{C}$, respectively using Sednterp.

\section{Method}

Sedimentation equilibrium analysis was conducted at $20^{\circ} \mathrm{C}$ using a single speed of $55,000 \mathrm{RPM}$ and 2 loading concentrations, 0.3 , and $1.0 \mathrm{mg} / \mathrm{mL}$, for each sample. Interference optics were used with a Beckman-Coulter XL-I analytical ultracentrifuge. Standard, double-sector aluminumfilled Epon cells equipped with sapphire windows were used, filling the reference side with 360 $\mu \mathrm{L}$ of buffer and the sample side with $15 \mu \mathrm{L}$ of FC-43 (an inert oil) plus $335 \mu \mathrm{L}$ of the appropriate sample. This resulted in solution column heights of $\sim 0.9 \mathrm{~cm}$. Interference scans were acquired at 6 minute intervals and attainment of equilibrium was determined using the "Match" module of the program HeteroAnalysis ${ }^{8}$. Cell blanks were acquired at 55,000 RPM prior to the actual run by filling the cells with water in both the reference and samples sides. The rotor was accelerated to speed and after 30 minutes scans were recorded for each cell for use as cell blanks. The water was removed from the cells after the blank scans were recorded, without disassembly of the cells, and they were dried in a vacuum prior to their use in the actual run. 


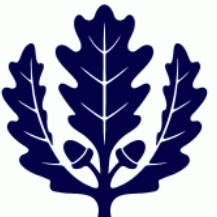

Program

\section{University of Connecticut}

James L. Cole \& Jeffrey W. Lary

Analytical Ultracentrifugation Facility

Biotechnology • Bioservices Center

\section{Analysis - 1}

HeteroAnalysis ${ }^{8}$, version 1.1.0.60

\section{Method}

Model-based non-linear least squares analysis of sedimentation equilibrium data.

\section{Results}

CMP\#87:

Blank-subtracted sedimentation equilibrium data for the two loading concentrations of CMP\#87 was globally fit to a number of models using Heteroanalysis. The only model that gave good results was the model of a mixture of two, non-interacting species (denoted A and B). A screen capture of the best fits for the two cells are shown next and the results of the fit are given in the table below the plots. The residuals (shown at the bottom of each plot) are randomly distributed, indicating that this is a good model for the system.
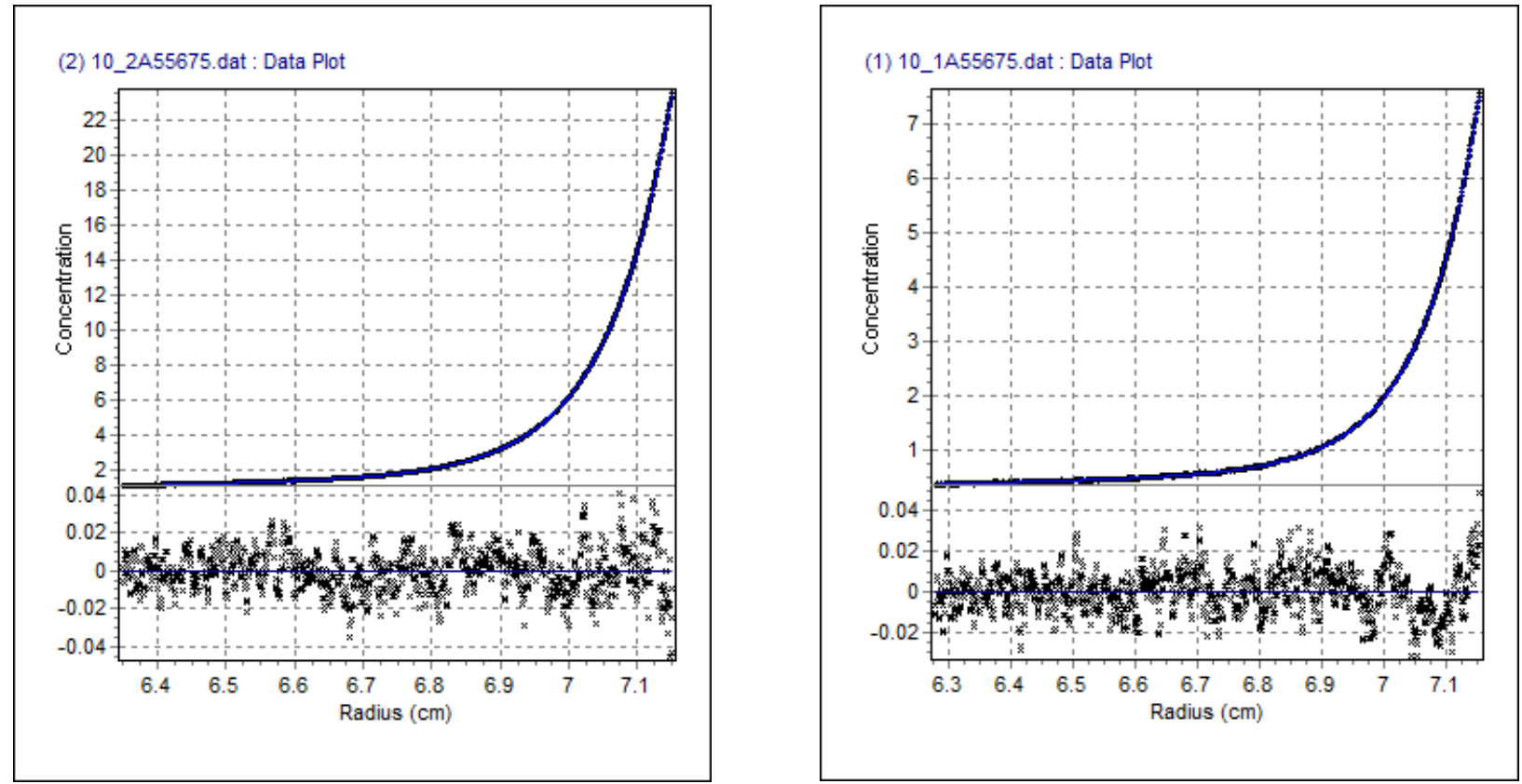

(The concentrations shown in the plots are in units of fringes, where $1 \mathrm{mg} / \mathrm{mL}=3.3$ fringes)

\begin{tabular}{|c|c|c|c|}
\hline Model & MW(A) (Da) & MW(B) (Da) & RMS (mg/ml) \\
\hline $\begin{array}{c}\text { Mixture of two, } \\
\text { ideal species }\end{array}$ & 250 & $3630[3610,3660]$ & 0.0034 \\
\hline
\end{tabular}

$*$ Numbers in the brackets are the $95 \%$ confidence limits of the fitted values.

The fitted molecular weight is within $7 \%$ of the sequence value for the trimer of CMP\#87. This is a quite good estimate keeping in mind that the partial specific volume $(\bar{v})$ that was calculated for the protein is, at best, a close approximation. 


\section{Analysis-1}

\section{Results (cont'd)}

CMP\#88:

Blank-subtracted sedimentation equilibrium data for the two loading concentrations of CMP\#88 was globally fit to a number of models using Heteroanalysis. As with the CMP\#87 sample, the only model that gave good results was the model of a mixture of two, non-interacting species (denoted $A$ and $B$ ). A screen capture of the best fit is shown next followed by a table containing the fitted values for the molecular weights of the two species. Here too, the random nature of the residuals is a good indication that this is an appropriate model for the data.
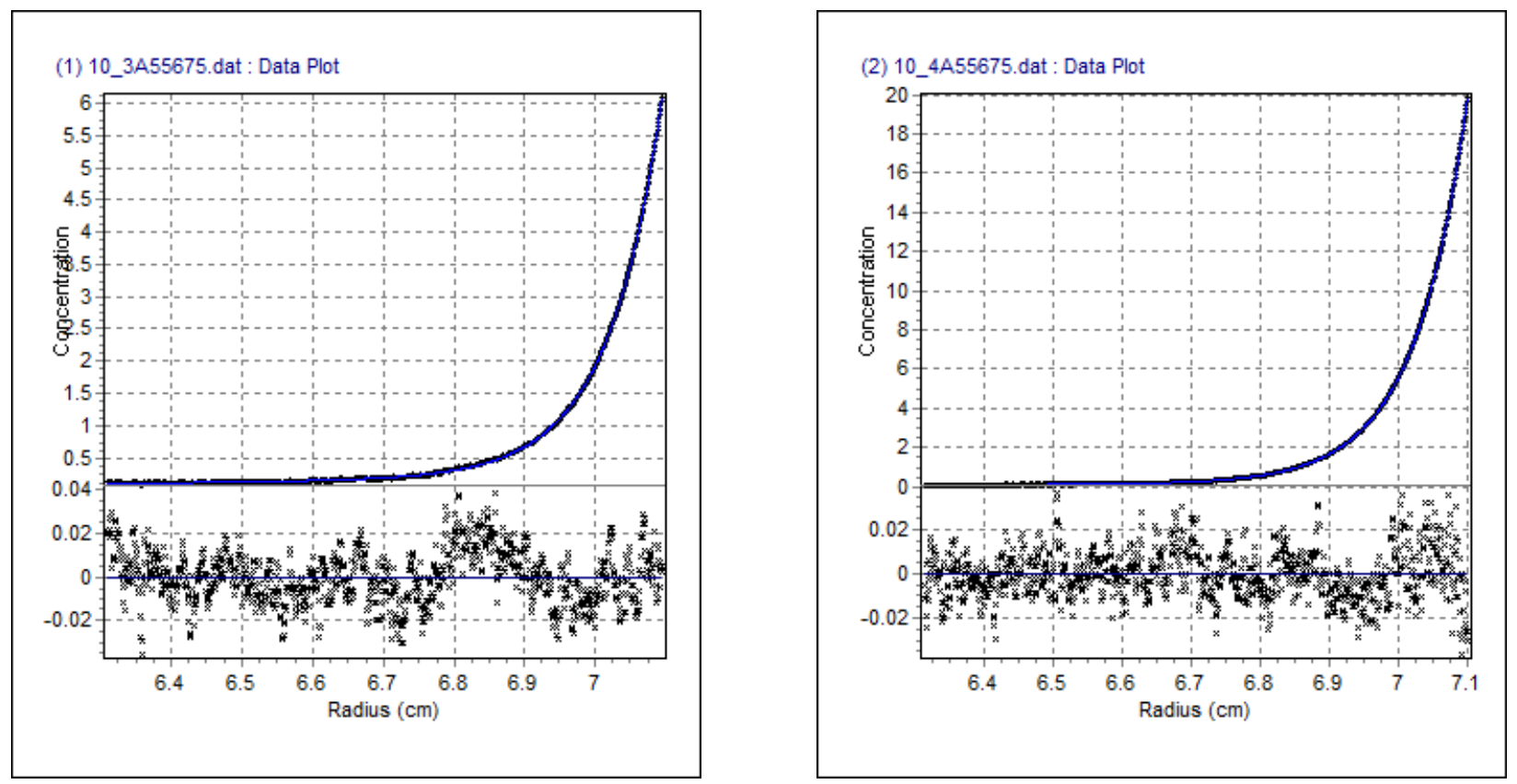

(The concentrations shown in the plots are in units of fringes, where $1 \mathrm{mg} / \mathrm{mL}=3.3$ fringes)

\begin{tabular}{|c|c|c|c|}
\hline Model & MW(A) (Da) & MW(B) (Da) & RMS (mg/ml) \\
\hline $\begin{array}{c}\text { Mixture of two, } \\
\text { ideal species }\end{array}$ & 390 & $4480[4460,4510]$ & 0.0035 \\
\hline
\end{tabular}

* Numbers in the brackets are the $95 \%$ confidence limits of the fitted values.

Unfortunately, we cannot estimate the relative amounts of each species contained in the sample using this program. 


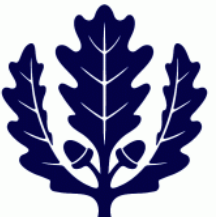

Program

Sedanal ${ }^{6}$, version 5.60

\section{Method}

Direct boundary modeling program for global analysis (i.e. multiple data sets) of sedimentation velocity data using model based numerical solutions to the Lamm equation.

\section{Model}

Mixture of two ideal components.

\section{Results}

\section{CMP\#87:}

The data set for CMP\#87 was analyzed using Sedanal with the model of two, non-interacting ideal species - A and B. The fitting parameters were the molecular weights of the two species, the baseline (fringe offset), and the loading concentration of components $A$ and $B$ for each cell. A screen capture of the best fit is shown below. The random nature of the deviations (blue plotted points) and the low RMS deviation for the fit indicates that this is a good model for this system.

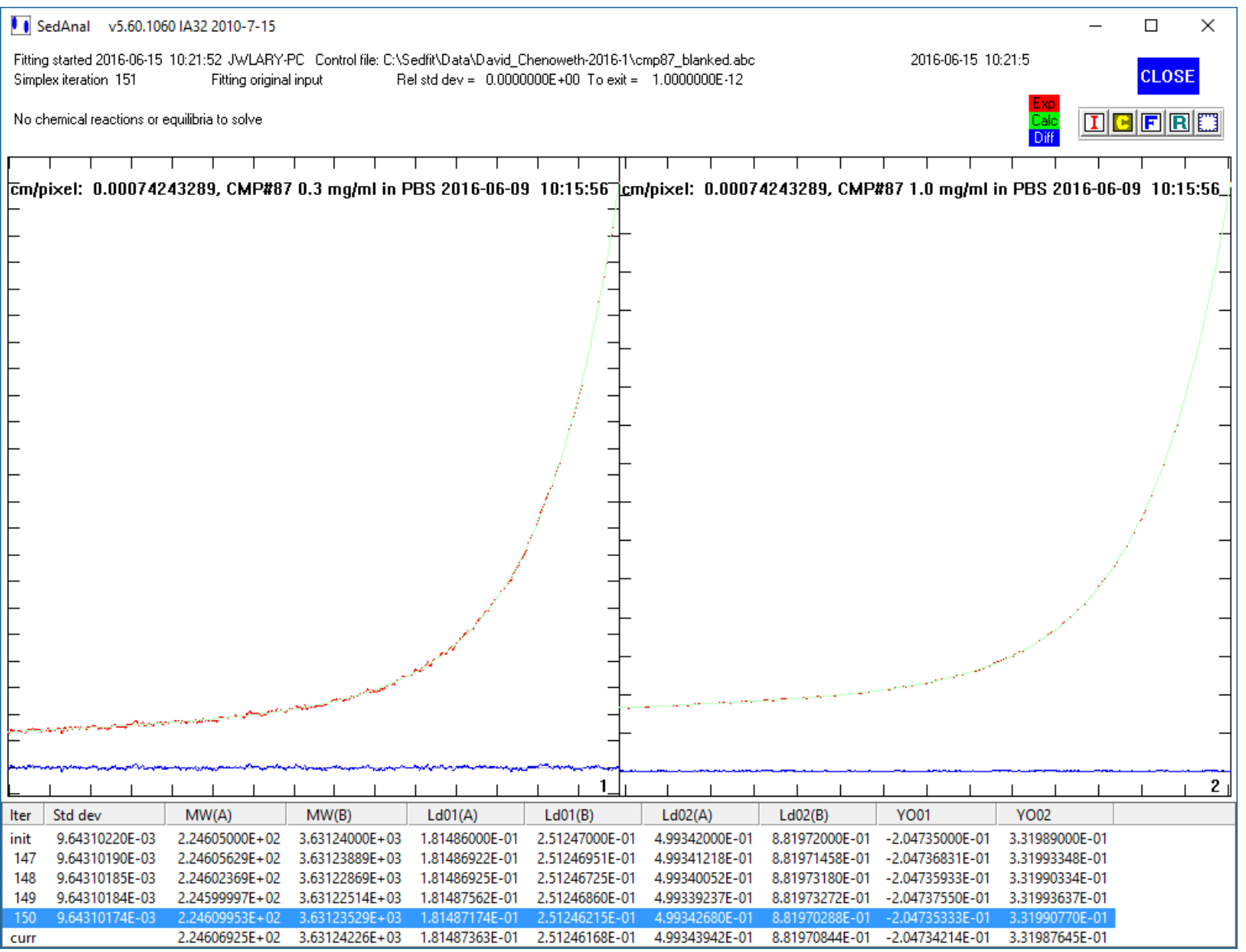




\section{University of Connecticut}

James L. Cole \& Jeffrey W. Lary

Analytical Ultracentrifugation Facility

Biotechnology • Bioservices Center

15June2016

\section{Analysis-2}

\section{Results (cont'd)}

The results of the fit are given in the table below.

\begin{tabular}{|c|c|c|c|c|c|}
\hline \multirow{2}{*}{ Model } & \multirow{2}{*}{ MW(A) (Da) } & \multirow{2}{*}{ MW(B) (Da) } & \multicolumn{2}{|c|}{ Weight \% } & \multirow{2}{*}{$\begin{array}{c}\text { RMS } \\
\text { (mg/ml) }\end{array}$} \\
\cline { 4 - 5 } & & Mixture of \\
$\begin{array}{c}\text { two, ideal } \\
\text { species }\end{array}$ & 225 & $3630[3610,3700]$ & $0.3 \mathrm{mg} / \mathrm{ml}-42 \%$ & $0.3 \mathrm{mg} / \mathrm{ml}-58 \%$ & \multirow{2}{*}{0.0029} \\
\hline
\end{tabular}

* Numbers in the brackets are the $95 \%$ confidence limits of the fitted values.

\section{CMP\#88:}

The data set for CMP\#88 was analyzed using Sedanal with the model of two, non-interacting ideal species - A and B. The fitting parameters were the molecular weights of the two species, the baseline (fringe offset), and the loading concentration of components $A$ and $B$ for each cell. $A$ screen capture of the best fit is shown below. The random nature of the deviations (blue plotted points) and the low RMS deviation for the fit indicates that this is a good model for this system.

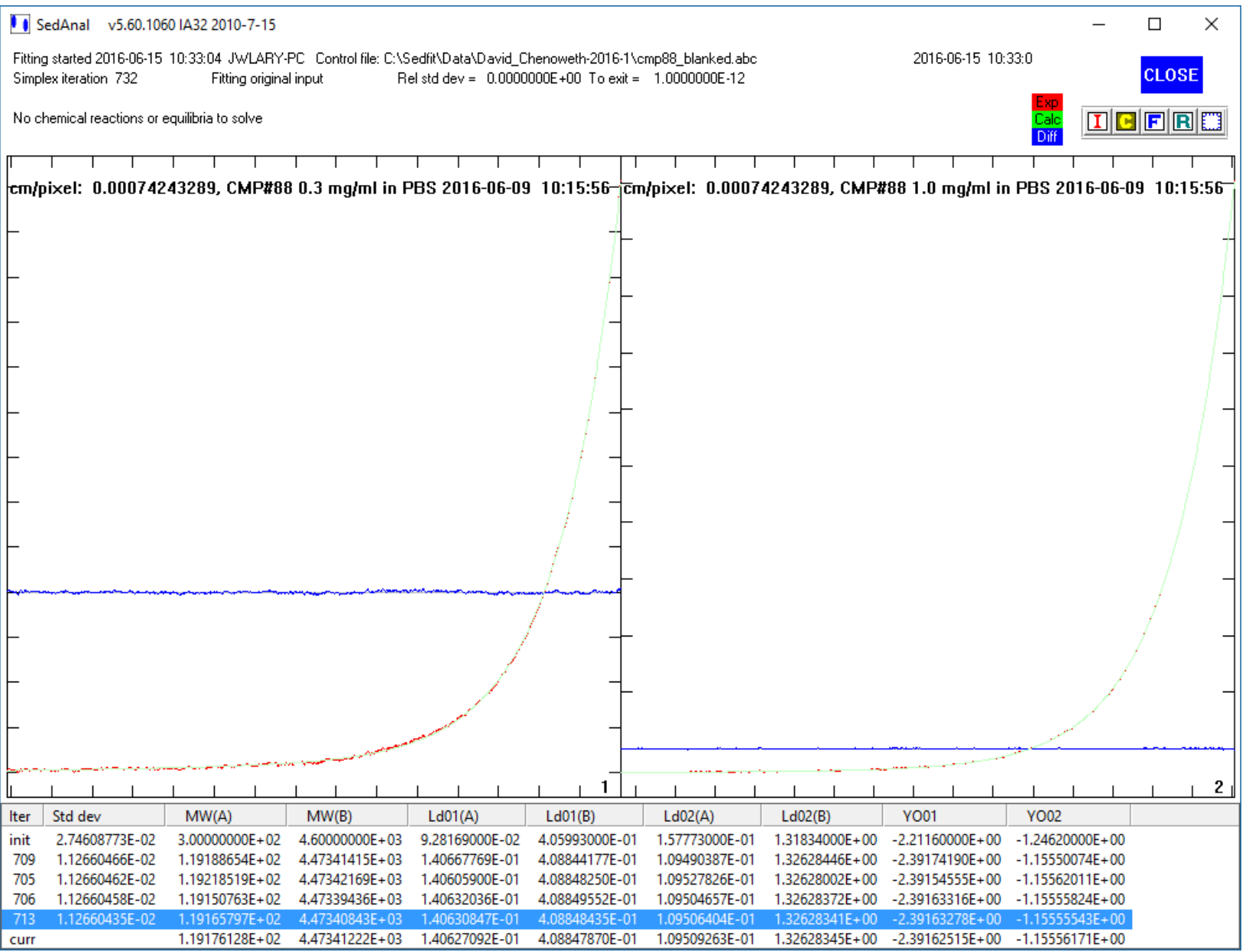




\section{University of Connecticut}

James L. Cole \& Jeffrey W. Lary

Analytical Ultracentrifugation Facility

Biotechnology $\bullet$ Bioservices Center

\section{Analysis-2}

\section{Results (cont'd)}

The results of the fit are given in the table below.

\begin{tabular}{|c|c|c|c|c|c|}
\hline \multirow{2}{*}{ Model } & \multirow{2}{*}{ MW(A) (Da) } & \multirow{2}{*}{ MW(B) $(\mathrm{Da})$} & \multicolumn{2}{|c|}{ Weight \% } & \multirow{2}{*}{$\begin{array}{c}\text { RMS } \\
(\mathrm{mg} / \mathrm{ml})\end{array}$} \\
\cline { 4 - 5 } & & $\mathrm{A}$ & $\mathrm{B}$ & \\
\hline $\begin{array}{c}\text { Mixture of } \\
\text { two, ideal } \\
\text { species }\end{array}$ & 120 & $4470[4460,4490]$ & $\begin{array}{c}0.3 \mathrm{mg} / \mathrm{ml}-26 \% \\
1.0 \mathrm{mg} / \mathrm{ml}-8 \%\end{array}$ & $\begin{array}{c}0.3 \mathrm{mg} / \mathrm{ml}-74 \% \\
1.0 \mathrm{mg} / \mathrm{ml}-92 \%\end{array}$ & 0.0034 \\
\hline
\end{tabular}

* Numbers in the brackets are the $95 \%$ confidence limits of the fitted values. 


\section{University of Connecticut \\ James L. Cole \& Jeffrey W. Lary \\ Analytical Ultracentrifugation Facility \\ Biotechnology $\bullet$ Bioservices Center}

15June2016

\section{Analysis - 3}

\section{Program}

Sedphat $^{9}$, version $12.1 \mathrm{~b}$

\section{Method}

Direct boundary modeling program for global analysis (i.e. multiple data sets) of sedimentation velocity and sedimentation equilibrium data using model based numerical solutions to the Lamm equation ${ }^{9}$.

\section{Model}

Global discrete species model.

\section{Results}

\section{CMP\#87:}

The blank-subtracted data from the two cells containing CMP\#87 was globally fitted using Sedphat and the model of a two, non-interacting, ideal species - A and B. The fitting parameters were the molecular weights of the two species, the baseline (fringe offset), total loading concentration, and weight fraction of B for each cell. A screen capture of the best fit is shown below. The random nature of the deviations (bottom plot) and the low RMS deviation for the fit indicates that this is a good model for this system.

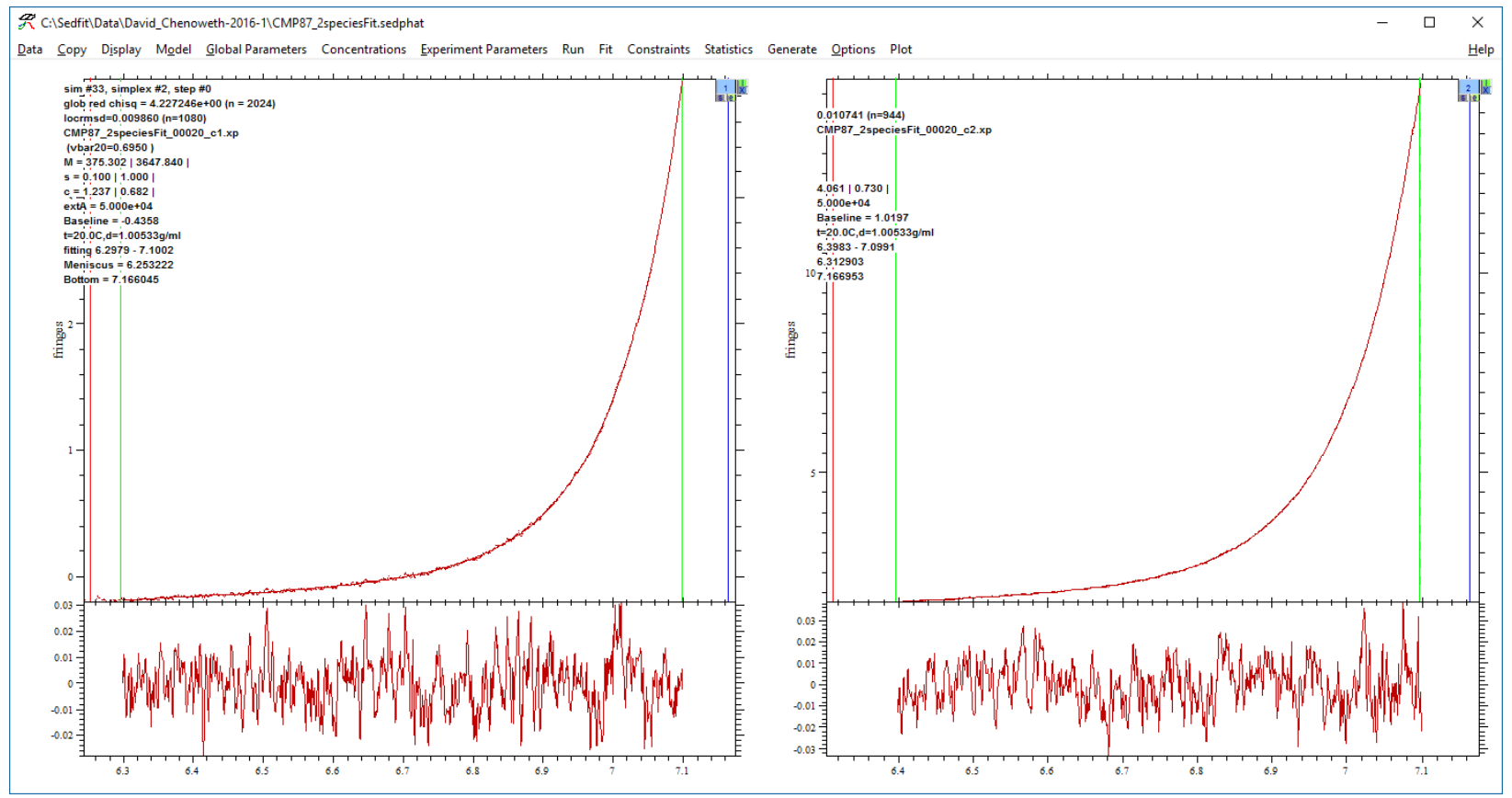

The results of the fit are given in the table below.

\begin{tabular}{|c|c|c|c|c|c|}
\hline \multirow{2}{*}{ Model } & \multirow{2}{*}{ MW(A) (Da) } & \multirow{2}{*}{ MW(B) (Da) } & \multicolumn{2}{|c|}{ Weight \% } & \multirow{2}{*}{$\begin{array}{c}\text { RMS } \\
\text { (mg/ml) }\end{array}$} \\
\cline { 4 - 5 } & & Mixture of \\
$\begin{array}{c}\text { two, ideal } \\
\text { species }\end{array}$ & 375 & $3650[3630,3660]$ & $0.3 \mathrm{mg} / \mathrm{ml}-32 \%$ & $0.3 \mathrm{mg} / \mathrm{ml}-68 \%$ & \multirow{2}{*}{0.0031} \\
\hline
\end{tabular}

$*$ Numbers in the brackets are the $95 \%$ confidence limits of the fitted values. 


\section{University of Connecticut}

James L. Cole \& Jeffrey W. Lary

Analytical Ultracentrifugation Facility

Biotechnology $\bullet$ Bioservices Center

Results (cont'd)

\section{Analysis - 3}

\section{CMP\#88}

The data set for CMP\#88 was analyzed using Sedphat with the model of two, non-interacting, ideal species - A and B. The fitting parameters were the molecular weights of the two species, the baseline (fringe offset), total loading concentration, and weight fraction of $B$ for each cell. A screen capture of the best fit is shown below. The random nature of the deviations (bottom plot) and the low RMS deviation for the fit indicates that this is a good model for this system.

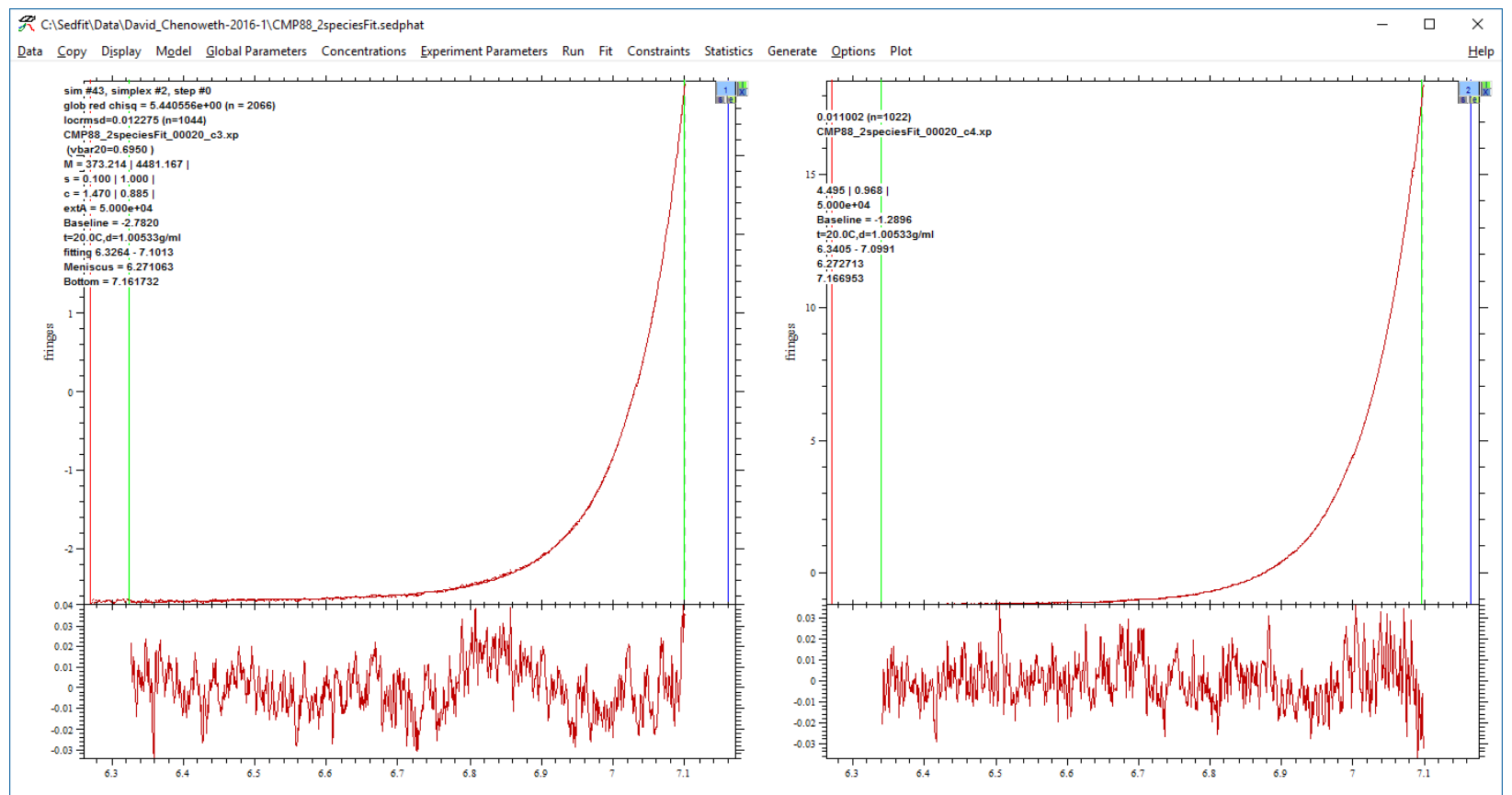

The results of the fit are given in the table below.

\begin{tabular}{|c|c|c|c|c|c|}
\hline \multirow{2}{*}{ Model } & \multirow{2}{*}{ MW(A) (Da) } & \multirow{2}{*}{ MW(B) (Da) } & \multicolumn{2}{|c|}{ Weight \% } & RMS \\
\cline { 3 - 5 } & & $\mathrm{mg} / \mathrm{ml})$ \\
\hline $\begin{array}{c}\text { Mixture of } \\
\text { two, ideal } \\
\text { species }\end{array}$ & 373 & $4480[4470,4490]$ & $\begin{array}{c}0.3 \mathrm{mg} / \mathrm{ml}-11 \% \\
1.0 \mathrm{mg} / \mathrm{ml}-3 \%\end{array}$ & $\begin{array}{c}0.3 \mathrm{mg} / \mathrm{ml}-89 \% \\
1.0 \mathrm{mg} / \mathrm{ml}-97 \%\end{array}$ & 0.0035 \\
\hline
\end{tabular}

* Numbers in the brackets are the $95 \%$ confidence limits of the fitted values. 


\section{University of Connecticut}

James L. Cole \& Jeffrey W. Lary

Analytical Ultracentrifugation Facility

Biotechnology $\bullet$ Bioservices Center

15June2016

\section{Summary}

The results from the SE run indicate that the CMP\#87 sample can be best modeled by a noninteracting mixture of two species. One species of $\sim 250$ Da comprising $\sim 35 \%$ of the material present and the second species with a molecular weight of $\sim 3630 \mathrm{Da}$ comprising $\sim 65 \%$ of the material present. The molecular weight of the second and more abundant species is consistent with that of the trimer of CMP\#87.

The CMP\#88 sample was also best modeled by a non-interacting mixture of two species. One species of $\sim 350 \mathrm{Da}$ comprising $\sim 15 \%$ of the material present, and the second species with a molecular weight of $\sim 4480$ Da comprising $\sim 85 \%$ of the sample. The molecular weight of the second and more abundant species is consistent with that of the trimer of CMP\#88. The following tables summarize the results from the various analyses for each sample.

\begin{tabular}{|c|c|c|c|c|c|}
\hline \multicolumn{6}{|c|}{ CMP\#87, Model: non-interacting mixture of two ideal species } \\
\hline \multirow{2}{*}{ Program } & \multicolumn{2}{|c|}{ MW (Da) } & \multicolumn{2}{|c|}{ Weight \% } & \multirow{2}{*}{$\begin{array}{c}\text { RMS } \\
(\mathrm{mg} / \mathrm{ml})\end{array}$} \\
\hline & A & $\mathrm{B}$ & A & $\mathrm{B}$ & \\
\hline HeteroAnalysis & 250 & $3630[3610,3660]$ & -- & -- & 0.0034 \\
\hline \multirow{2}{*}{ Sedanal } & \multirow{2}{*}{225} & \multirow{2}{*}{$3630[3610,3700]$} & $0.3 \mathrm{mg} / \mathrm{ml}-42 \%$ & $0.3 \mathrm{mg} / \mathrm{ml}-58 \%$ & \multirow{2}{*}{0.0029} \\
\hline & & & $1.0 \mathrm{mg} / \mathrm{ml}-36 \%$ & $1.0 \mathrm{mg} / \mathrm{ml}-64 \%$ & \\
\hline \multirow{2}{*}{ Sedphat } & \multirow{2}{*}{375} & \multirow{2}{*}{$3650[3630,3660]$} & $0.3 \mathrm{mg} / \mathrm{ml}-32 \%$ & $0.3 \mathrm{mg} / \mathrm{ml}-68 \%$ & \multirow{2}{*}{0.0031} \\
\hline & & & $1.0 \mathrm{mg} / \mathrm{ml}-27 \%$ & $1.0 \mathrm{mg} / \mathrm{ml}-73 \%$ & \\
\hline
\end{tabular}

* Numbers in the brackets are the $95 \%$ confidence limits of the fitted values.

\begin{tabular}{|c|c|c|c|c|c|}
\hline \multicolumn{6}{|c|}{ CMP\#88, Model: non-interacting mixture of two ideal species } \\
\hline \multirow{2}{*}{ Program } & \multicolumn{2}{|c|}{ MW (Da) } & \multicolumn{2}{|c|}{ Weight \% } & \multirow{2}{*}{$\begin{array}{c}\mathrm{RMS} \\
(\mathrm{mg} / \mathrm{ml})\end{array}$} \\
\hline & A & B & A & B & \\
\hline HeteroAnalysis & 390 & $4480[4460,4510]$ & -- & -- & 0.0035 \\
\hline Sedanal & 120 & $4470[4460,4490]$ & $\begin{array}{c}0.3 \mathrm{mg} / \mathrm{ml}-26 \% \\
1.0 \mathrm{mg} / \mathrm{ml}-8 \%\end{array}$ & $\begin{array}{l}0.3 \mathrm{mg} / \mathrm{ml}-74 \% \\
1.0 \mathrm{mg} / \mathrm{ml}-92 \%\end{array}$ & 0.0034 \\
\hline Sedphat & 373 & $4480[4470,4490]$ & $\begin{array}{c}0.3 \mathrm{mg} / \mathrm{ml}-11 \% \\
1.0 \mathrm{mg} / \mathrm{ml} \mathrm{-} \mathrm{3 \%}\end{array}$ & $\begin{array}{l}0.3 \mathrm{mg} / \mathrm{ml}-89 \% \\
1.0 \mathrm{mg} / \mathrm{ml}-97 \%\end{array}$ & 0.0035 \\
\hline
\end{tabular}

* Numbers in the brackets are the $95 \%$ confidence limits of the fitted values. 


\section{University of Connecticut}

James L. Cole \& Jeffrey W. Lary

Analytical Ultracentrifugation Facility

Biotechnology $\bullet$ Bioservices Center

15June2016

\section{References}

1. Philo, J. S. (2000). A method for directly fitting the time derivative of sedimentation velocity data and an alternative algorithm for calculating sedimentation coefficient distribution functions. Analytical Biochemistry 279, 151-163.

2. Philo, J. S. (2006). Improved methods for fitting sedimentation coefficient distributions derived by time-derivative techniques. Analytical Biochemistry 354, 238-246.

3. Schuck, P. (2000). Size distribution analysis of macromolecules by sedimentation velocity ultracentrifugation and Lamm equation modeling. Biophysical Journal 78:1606-1619.

4. Stafford, W.F., III. (1992). Boundary analysis in sedimentation transport experiments: A procedure for obtaining sedimentation coefficient distributions using the time derivative of the concentration profile. Analytical Biochemistry 203, 295-301.

5. T.M. Laue, B.D. Shah, T.M. Ridgeway and S.L. Pelletier, Analytical Ultracentrifugation in Biochemistry and Polymer Science, Royal Society of Chemistry (Edited by S. Harding and A. Rowe), 1992, pp. 90-125.

6. Walter F. Stafford and Peter J. Sherwood (2004). Analysis of heterologous interacting systems by sedimentation velocity: Curve fitting algorithms for estimation of sedimentation coefficients, equilibrium and kinetic constants. Biophysical Chemistry 108: 231-243.

7. J. Garcia de la Torre, M.L. Huertas and B. Carrasco (2000). Calculation of hydrodynamic properties of globular proteins from their atomic-level structure. Biophysical Journal 78, 719730.

8. Cole, J.L. (2004). Analysis of heterogeneous interactions. Methods Enzymol. 384: 212-232.

9. Schuck, P. (2003). On the analysis of protein self-association by sedimentation velocity analytical ultracentrifugation. Analytical Biochemistry 320, 104-124. 